\title{
Root growth and presence of Rhizophagus irregularis distinctly alter substrate hydraulic properties in a model system with Medicago truncatula
}

\author{
Richard Pauwels $(\mathbb{D})$ Jan Jansa $(\mathbb{D})$ - David Püschel $(\mathbb{D}$ - Anja Müller $(\mathbb{D}$ • \\ Jan Graefe $(\mathbb{D}) \cdot$ Steffen Kolb (i) - Michael Bitterlich (D)
}

Received: 29 June 2020 / Accepted: 16 September 2020 / Published online: 30 September 2020

(C) The Author(s) 2020

\begin{abstract}
Aim We investigated how substrate hydraulic properties respond to the presence of arbuscular mycorrhizal fungi (AMF) in root-containing and root-free substrate zones in a Medicago truncatula-Rhizophagus irregularis model system.

Methods Before planting, two compartments constructed from standard soil sampling cores $\left(250 \mathrm{~cm}^{3}\right)$ were implanted into non-mycorrhizal and mycorrhizal pots containing a sand-zeolite-soil mix. One compartment allowed root penetration (1 $\mathrm{mm}$ mesh cover) and the other only hyphal ingrowth ( $42 \mu \mathrm{m}$ mesh cover). After eight weeks of growth under maintenance of moist conditions, the cores were subjected to water retention measurements. Additionally, we measured water retention of bare substrates before and after drying events to check for successful maintenance of moist conditions in pots. Results Drying of bare substrates decreased water retention, but planting at least sustained it. The parameters
\end{abstract}

Respnsible Editor: Janusz J. Zwiazek.

Electronic supplementary material The online version of this article (https://doi.org/10.1007/s11104-020-04723-w) contains supplementary material, which is available to authorized users.

R. Pauwels · A. Müller · J. Graefe · M. Bitterlich $(\bowtie)$ Leibniz Institute of Vegetable and Ornamental Crops e.V. (IGZ), Grossbeeren, Germany

e-mail: Bitterlich@igzev.de

J. Jansa

Laboratory of Fungal Biology, Institute of Microbiology of the

Czech Academy of Sciences, Prague, Czech Republic of water retention models responded linearly to root morphological traits across mycorrhizal and nonmycorrhizal substrates. Hyphae-only colonization comparatively affected the course of water retention in ways that suggest increased pore space heterogeneity while maintaining water storage capacity of substrates.

Conclusions Hence, water contents corresponded to different substrate matric potentials in non-mycorrhizal and mycorrhizal pots. We conclude that changes to water retention in AMF colonized substrates can contribute to a widely observed phenomenon, i.e. that mycorrhizal plants differ in their moisture stress response from non-mycorrhizal plants.

Keywords Arbuscular mycorrhiza $\cdot$ Medicago truncatula $\cdot$ Soil hydraulic properties $\cdot$ Water relations . Water retention - Root-free compartments .

Roots $\cdot$ Hyphae 


\section{Introduction}

Research on arbuscular mycorrhizal symbioses repeatedly reported that non-mycorrhizal plants and plants colonized by arbuscular mycorrhizal fungi (AMF) show distinct water consumption rates and physiological responses to certain moisture levels in the atmosphere and soil (Augé 2001, 2004; Augé et al. 2015; Bitterlich et al. 2019). The mechanisms responsible for changed water relations in the mycorrhizal scenario are, however, not as persuasively proven as those for nutrient delivery. While water molecules only accessible to AMF hyphae are found in higher quantities within mycorrhizal as compared to non-mycorrhizal plants (Püschel et al. 2020), the physiological relevance of direct hyphal water delivery has been judged equivocally (Allen 2007; Friese and Allen 1991; George et al. 1992; Püschel et al. 2020; Raven and Edwards 2001). However, a common finding is that plants engaged in arbuscular mycorrhizal symbioses deplete water from soils at higher rates and that physiological adjustments set in at different moisture levels than in plants that have not formed this symbiosis (Augé 2001; Augé et al. 2015). Technological advancements have allowed to prove that arbuscular mycorrhizal plants indeed differ from their non-mycorrhizal counterparts in their physiological and metabolic response to soil moisture, sometimes indicating a higher metabolic capacity to cope with water stress or to take up water (Aroca et al. 2007; Bárzana et al. 2014; Bitterlich et al. 2018c; Porcel et al. 2006; Porcel and Ruiz-Lozano 2004; Ruiz-Lozano et al. 1995; Zou et al. 2019).

In addition to hyphal water delivery and modulations in plant physiology by AMF, another trait may contribute to altered plant water relations in mycorrhizal plants. The mechanism could be found beyond the root zone. Indeed, the presence of AMF in soils or substrates may influence the physical constraints to water movement through the soil/substrate matrix and towards the roots (Augé et al. 2001; Bitterlich et al. 2018a). Since water flow is constrained to the pore space between solid particles, any rearrangement of soil particles and modulations in the wetting properties of the solid phase is expected to affect water extractability from and transport throughout the soils. Roots and soil fungi as members of the soil biota are considered integral contributors in a self-organizing system that modulates soils towards more porous, ordered and aggregated habitats with distinct (water) transport properties (Burr-Hersey et al.
2020; Feeney et al. 2006; Miller and Jastrow 2000; Ritz and Young 2004; Tisdall and Oades 1982). Yet, there is little direct experimental evidence of how strongly macroscopic soil hydraulic properties respond to AMF and whether such potential changes merit attention when plant moisture stress responses are studied (Bitterlich et al. 2018b; Querejeta 2017).

At the same time, there are numerous indirect indications that AMF influence the hydraulic properties of soils. One important is that AMF cause morphological responses of root systems (Berta et al. 1990; Gamalero et al. 2004; Wu et al. 2010). The growth and activity of root systems will lead to the formation of a highly connected biopore system and will determine the extent of clogging when roots grow into existing pores (Bodner et al. 2014; Głąb et al. 2013; Lucas et al. 2020; Wiersum 1957). When roots grow, they exert mechanical strength and move adjacent soil particles to accommodate their size increment (Bengough and MacKenzie 1994; Vollsnes et al. 2010). In order to grow, roots exude organic compounds into the adjacent pore space. The secretion of mucilage facilitates lubrication and reduces friction at the root-particle interface (Iijima et al. 2004). Components of the mucilage can lower the surface tension of water and mucilage preserves liquid bridges in the rhizosphere that maintain root-soil contact and a zone of high water content around roots (Ahmed et al. 2014; Burr-Hersey et al. 2020; Carminati et al. 2017, 2010; Helliwell et al. 2019; Kroener et al. 2018; Moradi et al. 2011; Read et al. 2003). Root-induced particle movement and exudation act jointly to aggregate soil particles within the root-influenced zone. Particle-particle contacts increase in the surrounding soil which are then glued together and stabilized against disintegration by the sticky and repellent properties of the plant-derived organic material (Ahmed et al. 2016; Hallett et al. 2003; Hallett et al. 2009; Materechera et al. 1994; Rillig and Mummey 2006; Vollsnes et al. 2010). These root-induced processes alter the size, the geometry and the wetting properties of the pore space around roots and, thus, affect soil hydraulic properties (Bodner et al. 2014; Kroener et al. 2018; Lucas et al. 2020; Read et al. 2003; Scholl et al. 2014). Hence, changes to soil hydraulic properties are expected as soon as AMF alter root system properties.

For AMF, abundant evidence exists for their involvement in the degree of soil aggregation (Leifheit et al. 2015, 2014; Morris et al. 2019; Rillig 2004; Rillig et al. 2015; Rillig and Mummey 2006; Rillig et al. 2002; 
Tisdall and Oades 1982; Wilson et al. 2009; Wright and Upadhyaya 1998). A so-called 'sticky string-bag' function has been assigned to the extraradical mycelium of AMF; acting as a binding agent for soil particles (Miller and Jastrow 2000). This is based on the direct access of AMF to plant-derived carbon that is then distributed into the soil. Besides that actively growing hyphae can clog pore space and may rearrange or align low-weight soil particles (Rillig and Mummey 2006; Ritz and Young 2004), AMF produce proteinaceous substances called glomalin which are released to the soil while hyphae being turned over (Driver et al. 2005; Gadkar and Rillig 2006). Glomalin persists in soils due to their comparatively low degradation rates (Steinberg and Rillig 2003). The abundance of glomalin is tightly correlated to aggregate stability in soils (Wright and Upadhyaya 1998) and the degree of soil aggregation increases with the abundance of AMF hyphae in soils (Wilson et al. 2009; Morris et al. 2019). Such aggregation processes result in changes to the size distribution of soil pores (Nimmo 2004b). Consequently, changes to soil pore size distribution upon AMF presence in soils have been observed by X-ray computed tomography (Martin et al. 2012). In addition, the idea has been communicated that AMF may also possess substances found in other filamentous fungi (e.g. amphiphilic hydrophobins), which can decrease the surface tension of water (Rillig 2005; Rillig and Mummey 2006) and, they can induce reppellent conditions on aggregate surfaces (Rillig et al. 2010). If these mechanisms manifest in AMF populated soils, they potentially affect how water is retained in and released from soils.

Quantitative measurements of macroscopic soil hydraulic properties are typically described by soil water retention curves; the relationship between the soil water content and the soil matric potential (Durner 1992; Rawls et al. 1991). Soil water retention is determined by how gravity counteracts capillary action and capillary action depends on adhesion, cohesion and on pore size. Hence, water retention curves measured on soils containing roots and AMF integrate their potential effects on soil wettability and on pore space geometry that together modulate how water can be extracted from soils. As soil water contents can be modulated experimentally by irrigation, possible alterations to the size distribution and wetting properties of the pore space due to AMF presence may affect the extractability of water, i.e. the matric potential encountered. This, however, has been studied only in a few instances (e.g. in Augé 2004;
Augé et al. 2001; Bitterlich et al. 2018c; Daynes et al. 2013) but it potentially affects the physical constraints to plant water extraction when AMF are involved (Bitterlich et al. 2018b). There essentially are three modes of action for such physical effects in the substrate: (i) AMF reshaping plant (root) growth, (ii) hyphal colonization of the substrate and, (iii) through affecting the microbes in the soil (shaping microbial communities, Jansa et al. 2013).

So far, we do not know of any study that investigated water retention in root-free and root-containing fractional volumes out of a planted bulk substrate of the same pots and compared the non-mycorrhizal and the mycorrhizal scenarios. This is surprising as it would inform us how the hydraulic properties would change in a whole microcosm that included both rooted and root-free zones. We therefore ask whether substrates in which a mycorrhizal plant grows differ in water retention from substrates of non-mycorrhizal systems and, if so, whether this is related to differences in root growth and whether the effects also extend to root-free substrate zones.

We designed a pot experiment using a well-known model system of Medicago truncatula plants, inoculated or not with an AMF isolate of Rhizophagus irregularis and grown in an artificial substrate mix. Our experimental set up allowed to investigate the water retention in root-free and root-containing soil/ substrate zones from the same pots at the same time. We assumed that the root-free and root-containing compartments emulate substrate patches that are both found in microcosm experiments.

\section{Material and methods}

Experimental setup and cultivation

The model legume $M$. truncatula 'J5' was sown into pots containing an artificial substrate mix and was inoculated or not with $R$. irregularis (Błaszk., Wubet, Renker \& Buscot) C. Walker \& A. Schüßler as ["irregulare"]. The pots contained two equally-sized small compartments, each buried in the pot substrate, with one compartment allowing ingrowth of roots and AMF and the other excluding ingrowth of roots. These compartments facilitated undisturbed harvesting of substrate fractions for measuring substrate water retention. 
Ten 4.3 $\mathrm{L}$ pots were filled with $5.6 \mathrm{~kg}$ of an air dry substrate mix each (with a bulk density of $1.3 \mathrm{~g} \mathrm{~cm}^{-3}$ ), consisting of $45 \%(\mathrm{v})$ of an autoclaved $\left(121{ }^{\circ} \mathrm{C}\right.$, $30 \mathrm{~min}$ ) quartz river sand with a grain size of $<4 \mathrm{~mm}$, $45 \%$ (v), of autoclaved zeolite with a grain size of 1$2.5 \mathrm{~mm}$ (Zeopol Ltd., Břeclav, Czech Republic; www. zeopol.com) and of $10 \%$ (v) $\gamma$-irradiated (> $25 \mathrm{kGy}$; Bioster, Corp, Czech Republic) soil from Tänikon, Switzerland $\left(47^{\circ} 29^{\prime} 10.0^{\prime \prime} \mathrm{N}, 8^{\circ} 55^{\prime} 10.1^{\prime \prime}\right.$ E). The soil sampled from 0 to $20 \mathrm{~cm}$ depth was an Orthic Luvisol containing $51 \%$ sand, $31 \%$ silt, $16 \%$ clay, and $2 \%$ soil organic matter (Jansa et al. 2003). The components were thoroughly homogenized and water retention of such a mix resembled that of a loamy sand. The substrate mix had a $\mathrm{pH}$ of 7.52, total organic carbon (C) and total nitrogen $(\mathrm{N})$ concentrations of $0.186 \%$ and $0.012 \%$, respectively. The water extractable phosphorus $(\mathrm{P})$ concentration was $2.06 \mathrm{mg} \mathrm{kg}^{-1}$ and the total $\mathrm{P}$ was $73.06 \mathrm{mg} \mathrm{kg}^{-1}$ (Püschel et al. 2020). The pots were each amended with $14 \mathrm{mg} \mathrm{N}$ (as ammonium nitrate), $120 \mathrm{mg} \mathrm{K}, 60 \mathrm{mg} \mathrm{Mg}$ and $60 \mathrm{mg} \mathrm{Ca}$ in form of soluble sulfate or chloride salts by thoroughly mixing the nutrient solutions with the substrate. During cultivation the pots received three additional $\mathrm{N}$ amendments totaling $35 \mathrm{mg}$ of $\mathrm{N}$ per pot. Before planting, the pot water holding capacity was determined by saturating a filled pot and letting it drain until dripping stopped. The weight differences between the oven-dried substrate and the drained substrate corresponded to $22.17 \%$ gravimetric substrate moisture. This condition was maintained throughout the experiment by replacing the consumed water every day.

The seeds of $M$. truncatula 'J5' were surface sterilized (10\% sodium hypochlorite; $10 \mathrm{~min}$ ), rinsed with tap water and let germinate on autoclaved $\left(121{ }^{\circ} \mathrm{C}\right.$, $30 \mathrm{~min}$ ) quartz river sand. The seeds were sprayed with rhizobial inoculum of Sinorhizobium meliloti, strain LT10. This inoculum was grown in TY liquid medium (Somasegaran and Hoben 1994) on a shaker at $24{ }^{\circ} \mathrm{C}$ for 3 days. The bacteria were washed with $0.5 \%$ (w:v) aqueous $\mathrm{MgSO}_{4}$ solution and the suspension was then adjusted to the optical density of 0.7 at $600 \mathrm{~nm}$ (which corresponded to approximately $2 \times 10^{9}$ cells $\mathrm{mL}^{-1}$ ). After two days, four germinating seeds were placed to a groove in each experimental pot and four plants per pot were maintained in each pot throughout the experiment. The transplantation of seeds was accompanied with a second application of the rhizobial suspension, sprayed into the groove. Visual observation during root processing later confirmed successful nodulation of all plants.

Half of the pots (M) were inoculated with $10 \mathrm{~mL}$ of in vitro produced inoculum of $R$. irregularis isolate SYM5 kindly donated by Symbiom Ltd., Czech Republic (www.symbiom.cz) directly under the seeds, as described previously (Gryndler et al. 2018). By this procedure, no organic matter and no other inoculum-associated microorganisms other than the AMF-biomass was introduced. The other half of the pots were left non-inoculated by the AMF (NM). Within the experiment, all substrate compartments were prepared from the same substrate charge and then randomly assigned to treatments. Standard metal $250 \mathrm{ml}$ (diameter $=8 \mathrm{~cm}$, height $=5 \mathrm{~cm})$ soil sampling cores were used for the root-containing and root-exclusion compartments, which were completely filled with the potting substrate and compacted until an equal bulk density of $1.25 \mathrm{~g} \mathrm{~cm}^{-3}$ was achieved. The core openings were then covered with nylon meshes with an opening size of $1 \mathrm{~mm}$ (Uhelon 8S, Silk \& Progress, Ltd., Czech Republic) to allow root ingrowth, or with $42 \mu \mathrm{m}$ mesh size (Uhelon $130 \mathrm{~T}$ ) to exclude root ingrowth but to allow hyphae to enter. The compartments were introduced into the pots in a way that the cylinder opening covered the central section of the substrate filling level and the closed metal frame of the cylinder covered the radius from the center to the rim of the pot. Both cores were placed oppositely in the pot with a slight inclination angle of approx. $15^{\circ}$ from the vertical to allow roots of all orders to penetrate the core directly. The pot design is illustrated in the supplementary information (Fig. S1).

Ten pots $(5 \mathrm{NM}$ and $5 \mathrm{M}$ ) were prepared and arranged randomly in the glass house. The plants were grown for eight weeks under glass house conditions at 25: $18{ }^{\circ} \mathrm{C}$ (day: night). Natural light was supplemented with $400 \mathrm{~W}$ metal halide lamps set to $14 \mathrm{~h}$ photoperiod resulting in photosynthetically active radiation flux at plant level ranging between $370 \mu \mathrm{mol} \mathrm{m}^{-2} \mathrm{~s}^{-1}$ at midday and a minimum of $85 \mu \mathrm{mol} \mathrm{m} \mathrm{m}^{-2} \mathrm{~s}^{-1}$ at dawn or dusk.

After eight weeks of growth the plants and cores were harvested. The nylon meshes also secured undisturbed harvesting of the sampling cores. The root- 
containing cores were harvested by using a sharp knife for root severance along the net surface with the aim of minimizing disturbance to the inner core substrate. While harvesting, difficulties with severance of tightly mesh bound roots lead to disturbance in two of the inner core substrate volumes. These compartments were discarded.

In addition, we prepared two different unplanted control treatments $(N=6)$, one was prepared from the fresh substrate mix, the other one was subjected to two sequential dryings to air-dry conditions across six weeks under laboratory conditions. Firstly, the unplanted treatment with the fresh substrate should serve as the starting value and allows comparing how water retention properties change after a growing period. Secondly, since forces of soil cohesion strongly depend on water contents (Nimmo 2004a) and roots induce local drying within their proximity (Carminati et al. 2010; Segal et al. 2008), we needed to check whether we avoided strong drying effects on inner-core volumes by our irrigation management. In total, six treatments were subjected to water retention assessments: (i) an unplanted fresh substrate mix as the starting condition (Bare/initial), (ii) an unplanted and dried treatment (Bare/dried) as a control for abiotic drying effects, (iii) and (iv) as the planted treatment with root ingrowth for $\mathrm{M}(\mathrm{M}+$ roots) and $\mathrm{NM}(\mathrm{NM}+$ roots) pots, and (v) and (vi) as the planted treatment under the absence of roots for the inoculation treatments $(\mathrm{M}$ - roots, $\mathrm{NM}$ - roots).

After harvest, we checked whether equal packing of the cores was assured for every treatment. We did not detect any strong changes to dry bulk density or dry porosity upon treatments (Table S1). Hence, equal packing was successful and no significant particle movement across the meshes was observed. Any potential changes to hydraulic properties thus cannot be ascribed to differences in core filling levels or time-dependent increases in dry bulk density. These compartments were subject to soil hydraulic property analyses and quantification of root and fungal colonization.

\section{Water retention assessments}

We used the simplified evaporation method; a continuous drying of the samples under laboratory conditions (Schindler et al. 2010). After harvesting the sampling cores, the cores were water saturated for $24 \mathrm{~h}$ in a water bath and subjected to the HYPROPTM system (Meter group, Munich, Germany). Two tensiometers in different heights $(\mathrm{z}=$ $1.25 \mathrm{~cm}$ and $3.75 \mathrm{~cm}$ ) were introduced into the sampling cores into previously prepared holes. The tension was recorded every ten minutes and the cores were weighed two times a day to obtain gravimetric water loss data. The method returns the volumetric water content $(\Theta)$ as a function of tension $(\mathrm{h}, \mathrm{hPa})$ assuming that the geometric mean of $\mathrm{h}$ of both tensiometers equals the mean soil matric potential $(\Psi)$ in the core soil volume. The measurement is terminated when air enters the tensiometers and $\mathrm{h}$ drops to $0 \mathrm{hPa}$. The air entry point at $\mathrm{h}=8800 \mathrm{hPa}$ is a material constant of the tensiometer ceramic and was introduced as an additional point to extend the common measurement range of tensiometers (Schindler et al. 2010). After termination of the measurement the soil samples were oven dried $\left(105^{\circ} \mathrm{C}, 24 \mathrm{~h}\right)$ to obtain the soil dry weight.

For model parameterization, we adopted the approach of Bodner et al. 2013a, b, 2014). The authors showed that root-soil-interactions affect parameters of the Kosugi water retention model (Kosugi 1994) and that these parameters are suitable indicators for changes in structural porosity as modulated by soil moisture dynamics and root growth. These model parameters respond empirically to biotic and abiotic influences on soils (Bodner et al. 2014, 2013a; Hayashi et al. 2006; Leij et al. 2002; Scholl et al. 2014).

Several variants of the Kosugi model were fitted globally to the complete data set. The best fit to the data set was judged based on the RMSE and the AICc which penalizes model complexity. The Peters, Durner and Iden (PDI) variant of the unimodal Kosugi model (Iden and Durner 2014; Peters 2013, 2014) was identified as the most suitable for all the data sets. The goodness of treatment-wise model fits was sufficiently comparable across treatments (Fig. S2). The general form of the PDI retention forces the water content to zero at $10^{6.8} \mathrm{~cm}$ tension (Eq. 1):

$\Theta(h)=\left(\Theta_{\text {Sat }}-\Theta_{\text {Res }}\right) S^{c a p}+\Theta_{\text {Res }} S^{a d}$, 
where $\Theta\left[\mathrm{cm}^{3} \mathrm{~cm}^{-3}\right]$ is the volumetric water content, $\Theta_{\text {Sat }}\left[\mathrm{cm}^{3} \mathrm{~cm}^{-3}\right]$ is the saturated water content, $\Theta_{\operatorname{Res}}\left[\mathrm{cm}^{3} \mathrm{~cm}^{-3}\right]\left(\Theta_{\mathrm{Res}}=\Theta_{\mathrm{R}}\right.$ in Iden and Durner 2014) is the maximum water content for water adsorption, $\mathrm{S}^{\text {cap }}$ and $\mathrm{S}^{\mathrm{ad}}$ are the relative saturation of capillary and adsorptive water (Eq. 2):

$$
\begin{aligned}
& S^{\text {cap }}(h)=\left(\frac{\Gamma(h)-\Gamma_{0}}{1-\Gamma_{0}}\right) \text { with, } \\
& S^{a d}(h)=1+\left(\frac{1}{\log _{10}\left(h_{a}\right)-\log _{10}\left(h_{0}\right)}\right)\left(\log _{10}(h)-\log _{10}\left(h_{0}\right)+b \ln \left(1+\exp \frac{\log _{10}\left(h_{a}\right)-\log _{10}(h)}{b}\right)\right) \text { and, } \\
& \Gamma(h)=\frac{1}{2} \operatorname{erfc}\left[\frac{\ln \left(\frac{h}{h_{m}}\right)}{\sqrt{2 \sigma}}\right],
\end{aligned}
$$

where $\Gamma(\mathrm{h})$ is the Kosugi water retention function with the effective saturation $\Gamma[-]$ corresponding to $(\Theta-$ $\left.\Theta_{\text {Res }}\right) /\left(\Theta_{\text {Sat }}-\Theta_{\text {Res }}\right), \Gamma_{0}$ is the basic function for $h=h_{0}$, $\mathrm{h}_{0}$ is the tension at zero water content and was set to $10^{6.8} \mathrm{~cm}$ as the thermodynamically expected value. The parameter $h_{a}$ is the suction at air entry for the adsorptive retention, $\mathrm{h}_{\mathrm{m}}$ is the capillary tension at the median pore radius, $\sigma$ is the standard deviation of the logtransformed pore-size distribution and erfc[] denotes the complementary error function and $b$ is a shape parameter for the adsorptive function (Eq. 3) introduced as (Iden and Durner 2014):

$b=0.1+0.07 \sigma\left(1-\exp \left(-\left(\frac{\Theta_{\text {Res }}}{\Theta_{\text {sat }}-\Theta_{\text {Res }}}\right)^{2}\right)\right)$.

The parameters of interest for this study are $\Theta_{\text {Sat }}$, $\Theta_{\text {Res }}, h_{m}$ and $\sigma$ which are the saturated water content or wet porosity, the maximum adsorptive water content, the capillary tension at the median pore radius and the standard deviation of the pore size distribution, respectively. We used changes in the model parameters for considering treatment-induced shifts in water retention.

On some simulated water retention curves, we show how changes in these intrinsic parameters determine curve shape (Fig. 1).

We converted $h_{m}$ with the Young-Laplace equation to the more intuitive median pore radius $\mathrm{r}_{\mathrm{m}}$, as has been done by others for soil-water-air systems (Bodner et al. 2014; Kosugi and Hopmans 1998) to improve understandability for the reader. Just because $r_{m}$ would increase with water release towards the wet range. Still, as water release is affected by wetting properties (Read et al. 2003) we do not interpret it as a true pore radius.

Root morphology

After water retention measurements were completed, roots were collected from the root-containing sampling cores, cleaned with tap water and weighed after residual rinse water was removed by centrifugation in a common salad spinner. The washed off substrate was kept to determine the substrate dry weight. A subsample of approximately half of the root fresh weight $(\approx 0.7 \mathrm{~g})$ was analyzed with the WhinRHIZO Arabidopsis 2012b software (Regent Instruments, Québec, Canada). Afterwards, mean root diameters, root lengths, root surfaces and root volumes were up-scaled on weight basis to the total root mass extracted from the sampling core substrate.

Mycorrhizal quantification in roots and soils and nutrient analyses

Approx. $1 \mathrm{~g}$ of a representative fresh root sample was stained with the ink-vinegar method as described previously (Vierheilig et al. 1998). Fifty root pieces of each root sample were scored using the method of Trouvelot et al. (1986) and the infection frequency (F \%), mycorrhizal intensity (M \%) and arbuscule abundance (A \%) of the root system were computed using the Mycocalc software (https://www2.dijon.inra.fr/mychintec/Mycocalc-prg/). After all architectural analyses of the roots were finalized, the roots were freeze dried and milled and DNA extracted from the dry root powder (using $10 \mathrm{mg}$ sample weights) by using DNeasy Plant Mini kit (Qiagen), following 
Fig. 1 Simulated water retention curves of the substrate used when the median tension $\left(\mathrm{h}_{, \mathrm{m}}\right)$ was set and increased from 30 to 40 , when the standard deviation of the log-normal pore size distribution $(\sigma)$ was increased maximum adsorptive water content $\left(\Theta_{\text {Res }}\right)$ was increased from 15 to $20 \%$ and the saturated water content $\left(\Theta_{\text {Sat }}\right)$ was increased from 40 to $50 \%$ from 0.3 to 0.5 , when the

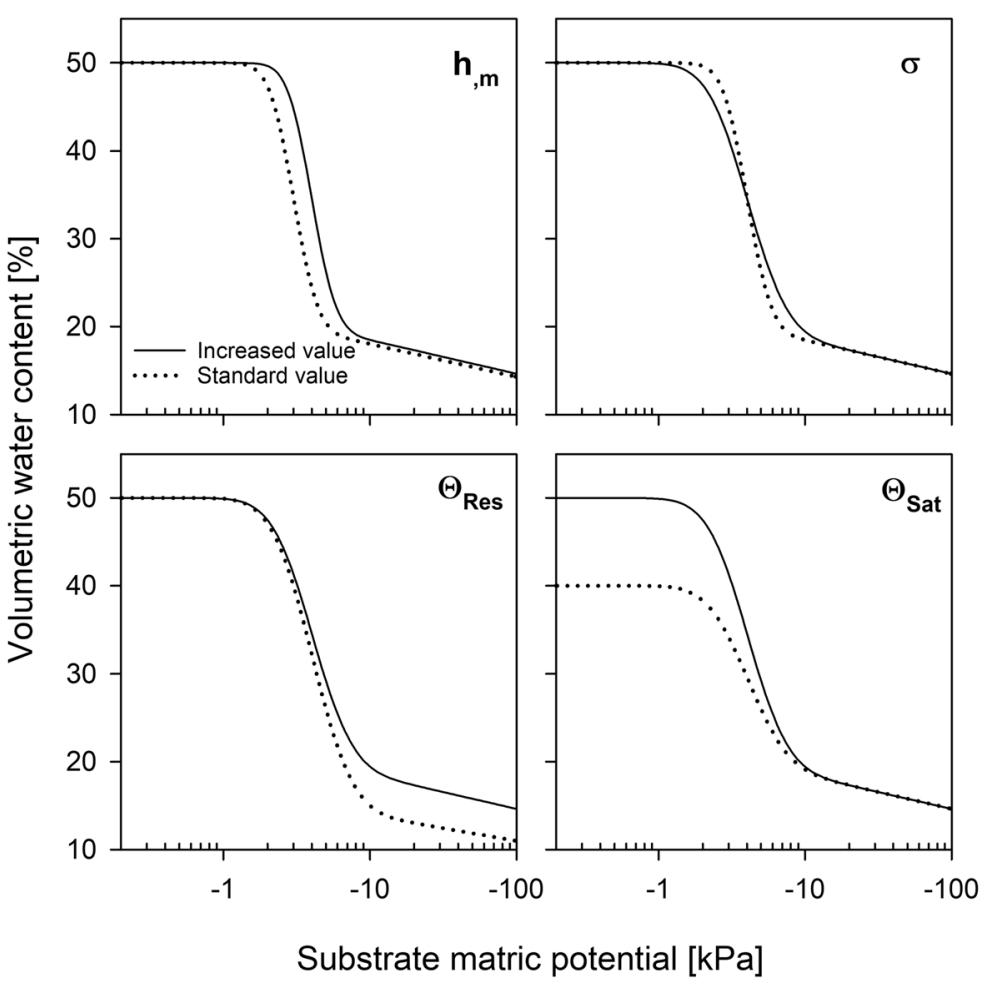

Statistics

manufacturer's instructions. Substrate samples were also freezer-dried and DNA extracted from $250 \mathrm{mg}$ aliquots using NucleoSpin Soil kit (Macherey-Nagel), following manufacturer's instructions and using SL1 extraction buffer and enhancer SX. Every sample (be it root or substrate) was spiked before DNA extraction with internal DNA standard as described previously (Thonar et al. 2012). Recovery rates of the internal standard in the DNA extract were quantified by quantitative realtime PCR (qPCR) as described previously (Thonar et al. 2012). Abundance of $R$. irregularis in each of the sample was quantified by the qPCR using the $\mathrm{mt} 5$ marker set (primers and a TaqMan probe) as described previously (Couillerot et al. 2013) to quantify copy number of mitochondrial large ribosomal subunit (mtLSU) gene of $R$. irregularis. The qPCR signal was corrected by the internal standard recovery. The abundance of the AMF was scaled up per unit volume of the pots by using sample weights and root and substrate densities estimated previously.

The $\mathrm{P}$ and $\mathrm{N}$ mass fractions in dry plant tissues were determined by incineration and spectrophotometry with Malachite Green and by standard $\mathrm{C} / \mathrm{N}$ analysis using Flash 2000 elemental analyzer (ThermoFisher Scientific), respectively (Püschel et al. 2017).
Statistical analyses assuming a cut-off level of $\alpha=0.05$ (t-test, regressions, normal distribution, variance homogeneity) were done with the STATISTICA 12 software (StatSoft, OK, Tulsa, USA). When variables tests for dependent samples were carried out. Illustrations were produced with SigmaPlot 12.3 (Systat software, GmbH, Erkrath, Germany). Model fitting quality (RMSE, AICc), parameter estimation, and coefficients of parameter correlations and computation of confidence intervals were done with the HYPROP-Fit software (Meter group, Munich, Germany). Overlapping 95\% confidence intervals of treatment specific curve shape parameters were interpreted as nonsignificant differences between the treatments.

\section{Results}

Plant growth, mycorrhization and root morphology

Mycorrhizal M. truncatula plants developed significantly higher plant dry weights than plants cultivated from different cores of the same pot were analyzed, $t$ - 
without $R$. irregularis. This was accompanied by increased $\mathrm{P}$ and $\mathrm{N}$ (for roots only) levels in tissues and, thus, in higher total plant $\mathrm{P}$ and $\mathrm{N}$ contents in mycorrhizal than in non-mycorrhizal plants (Table 1).

We used molecular quantification to assess mycorrhizal abundance. The mycorrhizal abundance in roots and in the root-free substrate was higher in the main pot volume than in the non-inoculated cores $(P=0.023$, Fig. 2). This was expected as colonization of cores required de novo colonization by either roots or AMF hyphae or it was related to certain degradation of AMF since the molecular quantification of AMF in cores took place a few days later after water retention measurements were terminated. Still, AMF colonization in the substrate (without roots) of root-containing cores neither differed from the substrate colonization in root-free cores $(P=0.328)$ nor from colonization in the main pot substrate $(P=0.055)$. The mtLSU copies of $R$. irregularis detected in roots from root-containing cores were in the same magnitude as detected in rootfree substrates $(P=0.107)$ and corresponded to a mean $( \pm \mathrm{SE})$ root infection frequency $(\mathrm{F})$ of $94 \pm 2.9 \%$, to mycorrhization intensity $(\mathrm{M})$ of $61 \pm 2.6 \%$ and an arbuscule abundance (A) of $33 \pm 5.7 \%$.

The larger mycorrhizal $M$. truncatula plants neither significantly modulated root length densities (M: $10.2 \mathrm{~cm} \mathrm{~cm}^{-3}$, NM: $8.8 \mathrm{~cm} \mathrm{~cm}^{-3}, P=0.661$ ), nor root surface densities (M: $1.23 \mathrm{~cm}^{2} \mathrm{~cm}^{-3}, \mathrm{NM}: 0.86 \mathrm{~cm}^{2} \mathrm{~cm}^{-3}$, $P=0.231$ ) or root volume densities (M: $0.012 \mathrm{~cm}^{3} \mathrm{~cm}^{-3}$, NM: $\left.0.007 \mathrm{~cm}^{3} \mathrm{~cm}^{-3}, P=0.056\right)$ inside root-containing cores, although total root mass in the main pot was higher in $\mathrm{M}$ pots than in NM pots. This indicates that root penetration of the cores occurred rather stochastically across NM and M pots. However, a comparatively coarser root system was observed in root-containing mycorrhizal cores (Fig. 3). The roots of plants associated with

Table 1 Shoot and root dry weights (DW) and leaf and root phosphorus $(\mathrm{P})$ and nitrogen $(\mathrm{N})$ mass fractions are shown for eight weeks old non-mycorrhizal (NM) and mycorrhizal (M)
$R$. irregularis were greater in volume and length than non-mycorrhizal plants, at diameters greater than $0.5 \mathrm{~mm}$ but smaller than $2 \mathrm{~mm}$. Consequently, the partial root system in root-containing cores of mycorrhizal pots had higher mean root diameters (M: $0.39 \mathrm{~mm}$, NM: $0.32 \mathrm{~mm}, P=0.043)$ and lower specific root lengths (M: $12.1 \mathrm{~cm} \mathrm{mg}^{-1}$, NM: $18.4 \mathrm{~cm} \mathrm{mg}^{-1} \mathrm{DW}, P=0.043$ ) than root systems of non-mycorrhizal plants.

Water retention as affected by drying, root growth and AMF colonization

When the water retention data separately obtained from root-free and root-containing substrate cores were pooled and fitted, M substrates showed an increase in water retention and a shallower decline in water contents with decreasing matric potentials than in all other treatments (Fig. 4a). In contrast, NM substrates showed similar water retention in the wet and dry range as bare/initial ones but the reduction in water contents were delayed to lower matric potentials (Fig. 4a). Drying of the bare substrate under laboratory conditions caused a decrease in wet-range water retention when compared to a non-desiccated bare substrate (Fig. 4b). When root ingrowth was allowed, water retention remained higher than in bare and dried substrates (Fig. 4 a,c). In general, the largest treatment-induced alterations in water retention relate to the range between $0 \mathrm{kPa}$ and $-1.5 \mathrm{kPa}$ which is within the expected range for biotic and structure related influences (e.g. Durner 1992).

In Fig. 4 the parameters showing non-overlapping CIs are highlighted and the complete list of the parameters of interest are given in Table 2. Desiccation of bare substrates caused a reduction in $\Theta_{\text {Sat }}$ and $\Theta_{\text {Res }}$ (Table 2). In contrast, the coarser root system in $\mathrm{M}$ pots than in $\mathrm{NM}$ pots caused a comparative increase in $\Theta_{\text {Sat }}$ and

M. truncatula plants inoculated with $R$. irregularis (t-test, $N=5$, $\pm \mathrm{SE}$ ). Significant differences ( $P$ values) at a cutoff level of $\alpha=$ 0.05 are highlighted in bold

\begin{tabular}{|c|c|c|c|c|c|c|}
\hline & \multicolumn{2}{|c|}{ Plant development } & \multicolumn{4}{|l|}{ Plant nutrition } \\
\hline & $\begin{array}{l}\text { Shoot } \\
{[\text { g DW] }}\end{array}$ & $\begin{array}{l}\text { Root } \\
{[\text { g DW] }}\end{array}$ & $\begin{array}{l}\text { Leaf P } \\
{\left[\mathrm{mg} \mathrm{g}^{-1} \mathrm{DW}\right]}\end{array}$ & $\begin{array}{l}\text { Root P } \\
{\left[\mathrm{mg} \mathrm{g}^{-1} \mathrm{DW}\right]}\end{array}$ & $\begin{array}{l}\text { Leaf } \mathrm{N} \\
{\left[\mathrm{mg} \mathrm{g}^{-1} \mathrm{DW}\right]}\end{array}$ & $\begin{array}{l}\text { Root } \mathrm{N} \\
{\left[\mathrm{mg} \mathrm{g}^{-1} \mathrm{DW}\right]}\end{array}$ \\
\hline M & $6.8 \pm 0.23$ & $2.8 \pm 0.21$ & $2.4 \pm 0.11$ & $2.8 \pm 0.13$ & $19.4 \pm 0.77$ & $22.3 \pm 0.65$ \\
\hline $\mathrm{NM}$ & $3.9 \pm 0.18$ & $1.8 \pm 0.11$ & $1.4 \pm 0.04$ & $1.6 \pm 0.05$ & $20.8 \pm 1.12$ & $19.9 \pm 0.49$ \\
\hline$P$ & $<0.001$ & 0.003 & $<0.001$ & $<0.001$ & 0.311 & 0.016 \\
\hline
\end{tabular}


Fig. 2 The abundance of $R$. irregularis as detected by quantitative real-time PCR in the roots (black) and in the substrate (squared pattern) in the different compartments in pots with M. truncatula. The asterisk indicates significant differences $(P<0.05 ; N=5 ; \pm \mathrm{SE}$; t-test for dependent samples)

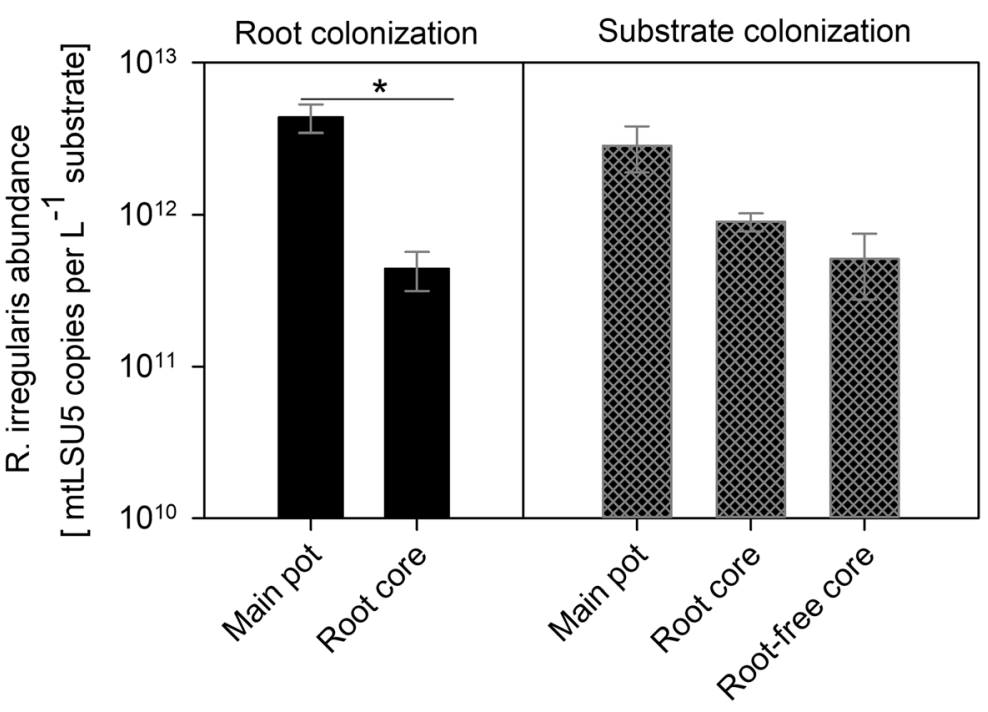

$\Theta_{\text {Res }}$ (Table 2). These parameters causing offsets in water retention in the wet and dry range were not affected when roots were excluded but hyphal penetration of the cores was allowed (Table 2, Fig. 4d). In contrast to root presence, hyphae-only colonization better conserved the median pore radius $\left(\mathrm{r}_{\mathrm{m}}\right)$ of bare substrates than when neither roots nor hyphae were present in the planted NM cores (Table 2). In addition, hyphae-only colonization increased the standard deviation of pore size distribution $(\sigma)$ in planted pots compared to the bare/initial substrates.

Since AMF modulated root system properties, we asked whether alterations in root morphology affected water release properties. We found that the curve shape parameters estimated from treatment-wise fits were considerably consistent with the mean of the parameter values of pot-specific fits (not shown). This gave us confidence that a pot specific correlation analysis on root containing cores is a valid approach.

This pot-specific correlation analyses revealed that the variation in water retention between $\mathrm{M}$ and $\mathrm{NM}$ substrates in root-containing cores is related to differences in root traits (Fig. 5). The model parameters shaping water retention related to the standard deviation of the pore size distribution $(\sigma), \Theta_{\text {Sat }}$ and $\Theta_{\text {Res }}$ were significantly correlated to the mean root diameter, the
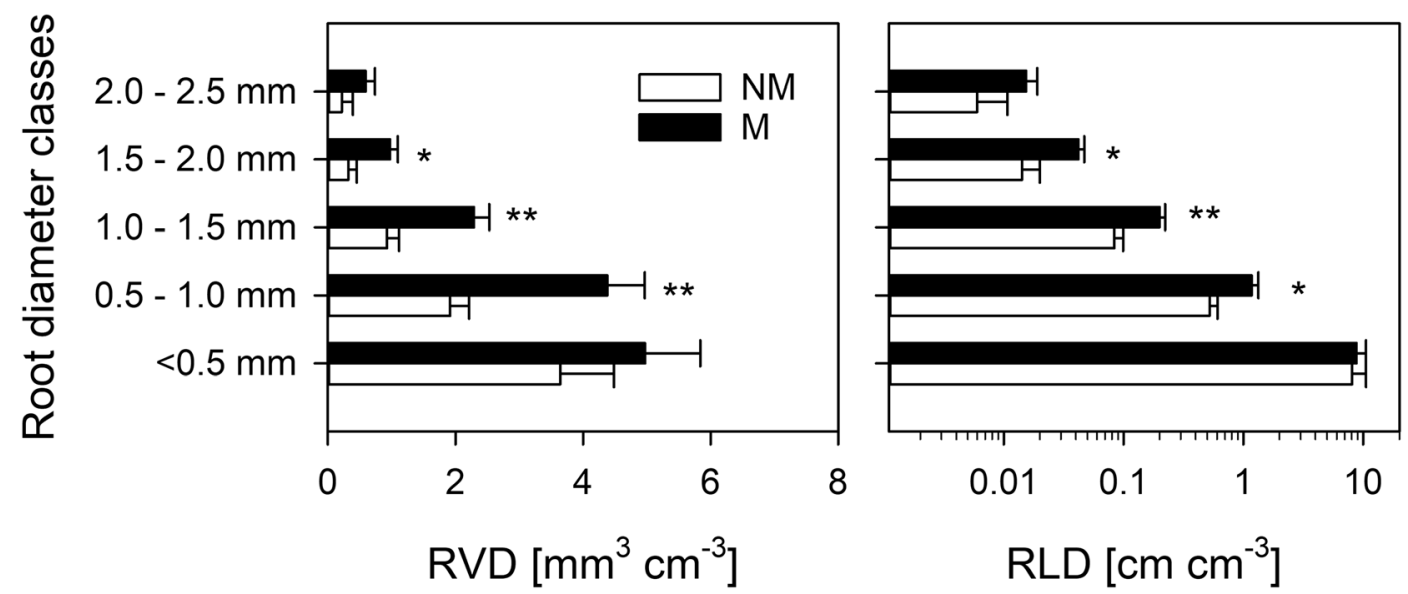

Fig. 3 The root volume density (RVD) and root length density (RLD) of non-mycorrhizal (NM, white) and M. truncatula root containing cores after water retention assessments. Asterisks indicate significant differences between non-mycorrhizal and mycorrhizal roots systems (t-test; $N=4 ; \pm \mathrm{SE}$; ${ }^{*}, P<0.05$; **, $P<0.01$ ) 
Fig. 4 Substrate water retention curves of bare and planted substrates (a) that remained either untreated (black), were subjected to two sequential dry-downs (grey) and of substrates either inoculated (M, blue) or not (NM, red) with R.irregularis where root-containing cores and rootfree cores were fitted together. Substrate water retention curves are also shown side-by-side for untreated and dried substrates (b), root-containing substrates (c) and substrates within the same pots were root growth was impeded by nylon meshes (d). The curves represent treatment-wise fits of the Kosugi PDI model (a: $N=6$ for unplanted treatments; $N=8$ for planted treatments, $\mathbf{b}: \mathrm{N}=6$, c: $N=4, \mathbf{d}: N=5)$. The curve shape parameters that showed nonoverlapping $95 \%$ CIs between treatments are given in $\mathrm{b}, \mathrm{c}$ and $\mathrm{d}$. A complete list of parameters is given in Table 2

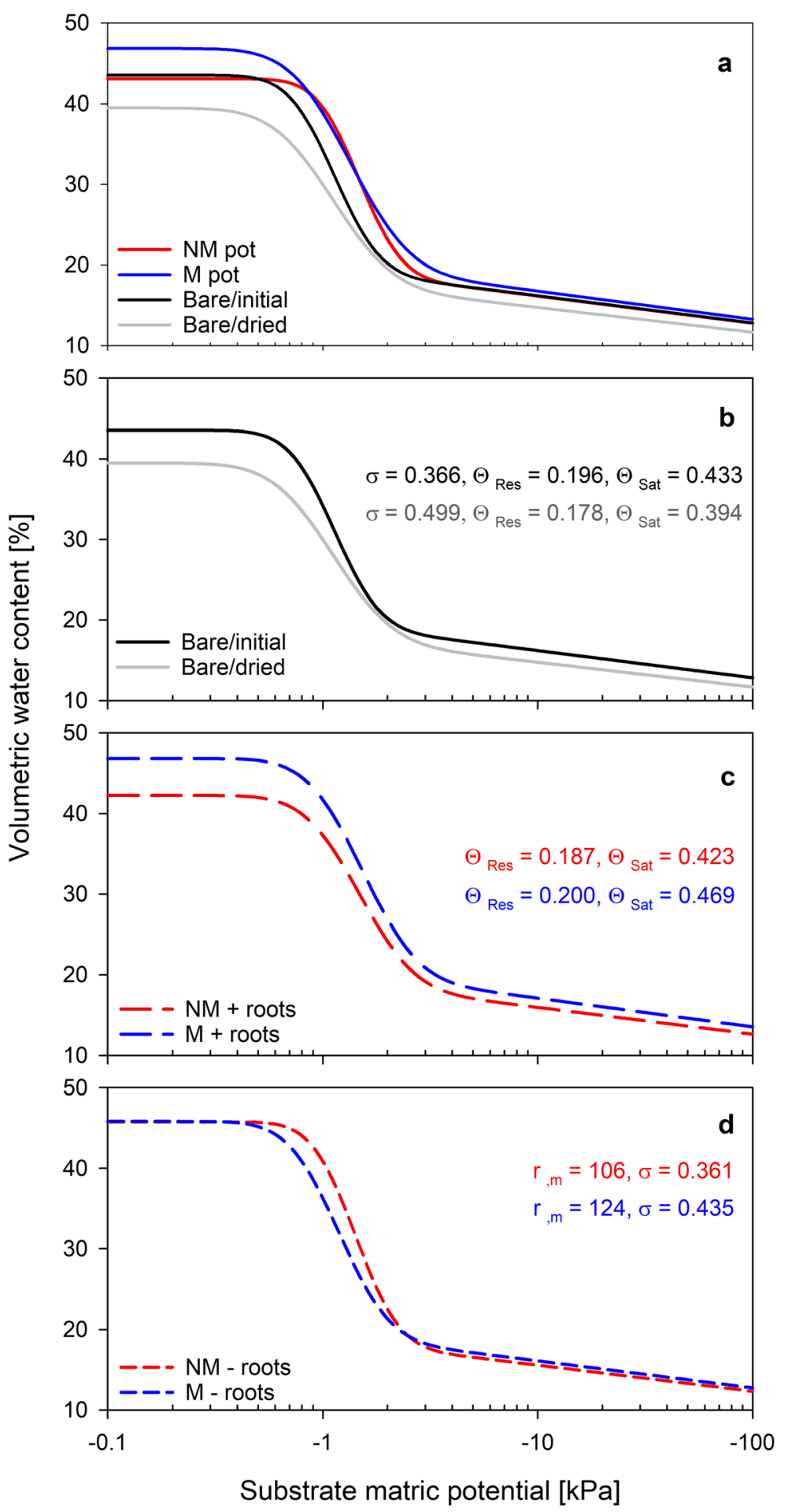

root volume density and the specific root length, respectively (Fig. 5). We did not find any treatment-induced changes to the median pore radius $\left(r_{, m}\right)$ in root- containing cores but this was generally lower compared to all other cores assessed (Table 2). This means that most of the variation in substrate water retention in root- 
Table 2 The median pore radii $\left(\mathrm{r}_{\mathrm{m}}\right)$, the standard deviation of the lognormal pore size distribution $(\sigma)$, the maximum water content for adsorptive retention $\left(\Theta_{\text {Res }}\right)$ and the saturated water content $(\Theta$ Sat) and the $95 \%$ CIs are given for untreated substrates $(\mathrm{N}=6)$, unplanted substrates subjected to drying $(N=6)$, for non-mycorrhizal (NM) and mycorrhizal (M) pots containing M. truncatula plants infected or not with $R$. irregularis. The planted (combined) treatment indicates that data from cores with and without roots were used simultaneously for fittings $(\mathrm{N}=8)$ for every treatment. The other parameters given derive from separate treatment wise model fittings ( $\mathrm{N}=4$ with roots, $\mathrm{N}=5$ without roots). Data in bold indicate non-overlapping CIs of parameters either between the bare/initial and bare/dried substrates or between NM and M substrates

\begin{tabular}{llllll}
\hline Core type & Treatment & $\mathrm{r}_{, \mathrm{m}}[\mu \mathrm{m}]$ & $\sigma[-]$ & $\Theta_{\operatorname{Res}}\left[\mathrm{cm}^{3} \mathrm{~cm}^{-3}\right]$ & $\Theta_{\mathrm{Sat}}\left[\mathrm{cm}^{3} \mathrm{~cm}^{-3}\right]$ \\
\hline Bare & Initial & $135 \pm 0$ & $\mathbf{0 . 3 6 6} \pm \mathbf{0 . 0 2 4}$ & $\mathbf{0 . 1 9 6} \pm \mathbf{0 . 0 0 4}$ & $\mathbf{0 . 4 3 3} \pm \mathbf{0 . 0 0 4}$ \\
& Dried & $135 \pm 0$ & $\mathbf{0 . 4 9 9} \pm \mathbf{0 . 0 1 3}$ & $\mathbf{0 . 1 7 8} \pm \mathbf{0 . 0 0 2}$ & $\mathbf{0 . 3 9 4} \pm \mathbf{0 . 0 0 1}$ \\
Planted (combined) & M & $\mathbf{1 1 4} \pm \mathbf{3}$ & $\mathbf{0 . 5 1 0} \pm \mathbf{0 . 0 3 5}$ & $0.198 \pm 0.007$ & $\mathbf{0 . 4 6 8} \pm \mathbf{0 . 0 0 5}$ \\
& NM & $\mathbf{9 9} \pm \mathbf{3}$ & $\mathbf{0 . 3 4 9} \pm \mathbf{0 . 0 2 2}$ & $0.190 \pm 0.005$ & $\mathbf{0 . 4 3 1} \pm \mathbf{0 . 0 0 3}$ \\
Planted & M + roots & $99 \pm 3$ & $0.471 \pm 0.038$ & $\mathbf{0 . 2 0 0} \pm \mathbf{0 . 0 0 8}$ & $\mathbf{0 . 4 6 8} \pm \mathbf{0 . 0 0 5}$ \\
& NM + roots & $99 \pm 3$ & $0.482 \pm 0.025$ & $\mathbf{0 . 1 8 6} \pm \mathbf{0 . 0 0 4}$ & $\mathbf{0 . 4 2 3} \pm \mathbf{0 . 0 0 2}$ \\
& M - roots & $\mathbf{1 2 4} \pm \mathbf{0}$ & $\mathbf{0 . 4 3 4} \pm \mathbf{0 . 0 2 1}$ & $0.192 \pm 0.005$ & $0.458 \pm 0.004$ \\
& NM - roots & $\mathbf{1 0 6} \pm \mathbf{0}$ & $\mathbf{0 . 3 6 4} \pm \mathbf{0 . 0 2 9}$ & $0.185 \pm 0.008$ & $0.457 \pm 0.006$ \\
\hline
\end{tabular}

containing substrates was explained by increases of the root volume. But when finer root systems colonized the substrate, the heterogeneity of water release from the pore space $(\sigma)$ increased and dry range water retention decreased $\left(\Theta_{\text {Res }}\right)$.

In contrast to drying, the widening of the water release pattern in substrates containing hyphae or roots $(\sigma$, Table 2 ) was not accompanied by reductions in wet porosity $\left(\Theta_{\text {Sat }}\right.$, Fig. 6). To further visualize what happened, we used an approach similar to that of Bodner et al. (2013b) and calculated the wet range water release $\left(\Theta_{-0 \mathrm{kPa}}-\Theta_{-1 \mathrm{kPa}}\right)$ from near saturated conditions. At this range, water retention is expected to change upon penetration of (large) roots and/or stabilized macropores between aggregates (Bodner et al. 2013b) but also when surface active solute concentrations in the soil water increase (Read et al. 2003). We found that $\Theta_{\text {Sat }}$ was generally sustained by planting while it declined in bare substrates that were dried (Fig. 6a). In contrast, wet range water release was sustained upon drying of bare substrates but root presence reduced it (Fig. 6b). Interestingly, hyphae-only penetration under root absence preserved wet range water release of bare substrates, while it declined strongly in root-free NM substrates (Fig. 6b).

These different curve shapes induced by treatments led to distinct matric potentials encountered under particular water contents (Table 3). Especially in the dry range where matric potentials strongly decline per unit change in water contents, $\mathrm{M}$ substrates had lower matric potentials than NM substrates at $15 \%$ and $10 \%$ volumetric water contents. Compared to the bare/initial substrate, it is worth highlighting that root-containing $\mathrm{M}$ substrates reduced matric potentials and NM substrates increased matric potentials at these water contents. In root-free substrates water retention seems to trend to induce similar effects as drying a bare substrate but hyphal presence alleviated the decline in matric potentials compared to bare substrates under lower water contents (Table 3).

\section{Discussion}

We found that the presence of AMF in substrates altered substrate water retention differently in root-free and root-containing substrate zones. Water retention in root-containing substrates increased when AMF were present. This was largely explained by AMF-induced changes to root morphological traits. In substrates in which roots were absent, presence of AMF reduced wet-range water retention and slightly increased dryrange water retention. Hence, substrate matric potentials encountered at equal water contents differed in pots containing mycorrhizal and non-mycorrhizal plants. Our results imply that equality in water extractability from substrates cannot always be assumed for mycorrhizal and non-mycorrhizal plants when they are managed for equal substrate water contents. 

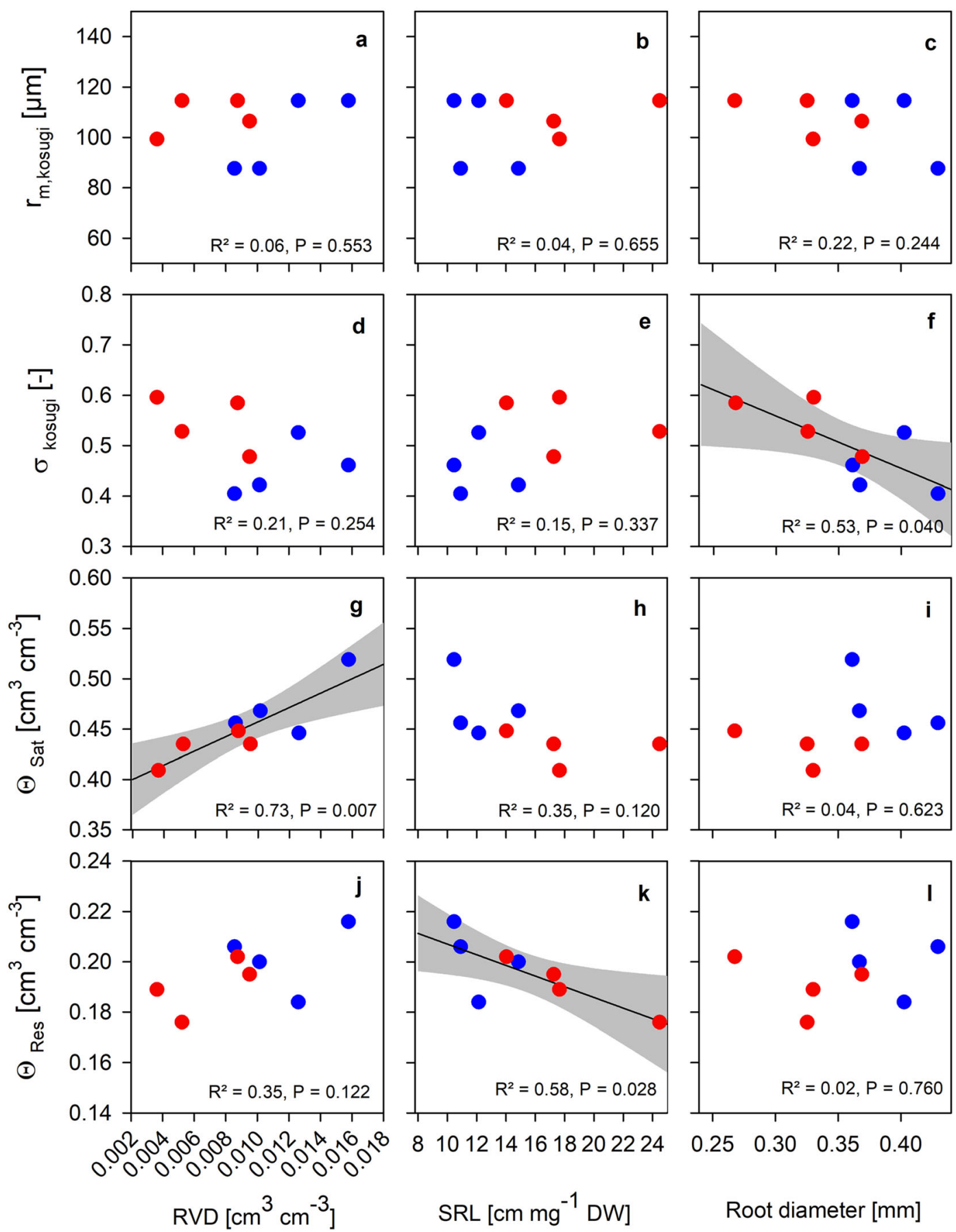

Fig. 5 Correlative analyses of the Kosugi PDI model parameters obtained by pot specific model fits of water retention measurements in substrate cores that allowed root ingrowth of M. truncatula plants either inoculated (blue) or not (red) with $R$. irregularis. The median pore radius $(\mathrm{r}, \mathrm{m} ; \mathbf{a}, \mathbf{b}, \mathbf{c})$, the standard deviation of the log-normal pore size distribution $(\sigma ; \mathbf{d}, \mathbf{e}, \mathbf{f})$, the
$\mathrm{SRL}\left[\mathrm{cm} \mathrm{mg}{ }^{-1} \mathrm{DW}\right]$ saturated water content $\left(\Theta_{\text {Sat }}, \mathbf{g}, \mathbf{h}, \mathbf{i}\right)$ and the maximum adsorptive water content $\left(\Theta_{\text {Res }}, \mathbf{j}, \mathbf{k}, \mathbf{l}\right)$ were correlated to the root volume density (RVD; a, d, g, j), the specific root length (SRL; b, e, h, k) and the mean root diameter $(\mathbf{c}, \mathbf{f}, \mathbf{i}, \mathbf{l})$ of roots contained in the substrate cores. Significant correlations are displayed by black lines and $95 \%$ CIs by grey areas $(N=8)$ 


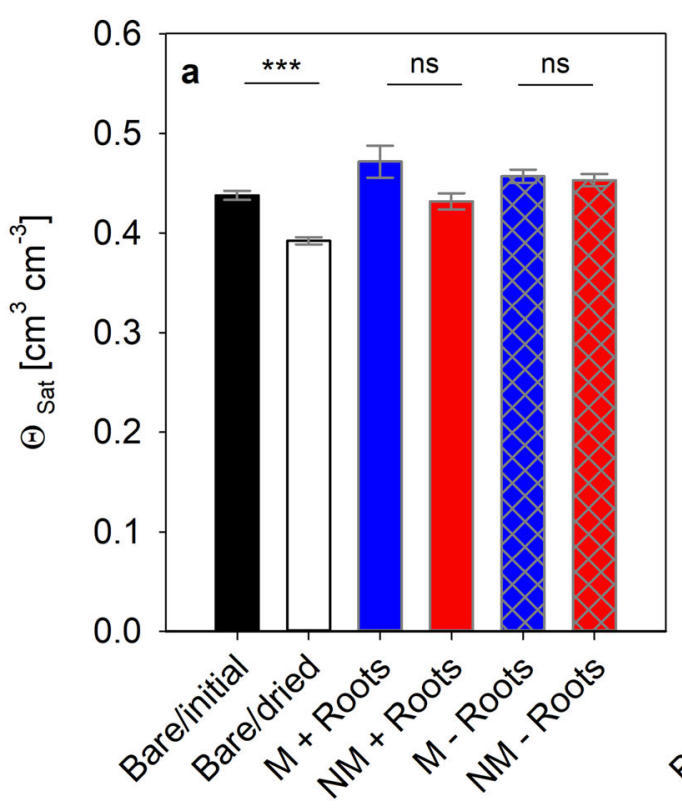

Fig. 6 The saturated water content $\left(\Theta_{\text {Sat }}\right.$, a) and the wet range water contents $\left(\Theta_{-0 \mathrm{kPa}}-\Theta_{-1 \mathrm{kPa}}, \mathbf{b}\right)$ for untreated (Bare/initial, black) and unplanted and dried (Bare/dried, white) substrates $(\mathrm{N}=6)$, for planted substrates containing roots (+ Roots, $\mathrm{N}=4$ ) or not ( - Roots, $\mathrm{N}=5$ ) for non-mycorrhizal (NM, red) and

\section{Abiotic and biotic effects on soil water retention}

Abiotic and biotic influences on soil water retention are often difficult to discern experimentally as they both could modulate pore space. For example, both root proliferation and climatically or experimentally induced wet-dry dynamics can move particles, consolidate or disintegrate particle aggregation, which in turn can alter pore space properties in, e.g. agricultural settings (Bodner et al. 2014, 2013a; Leij et al. 2002; Nimmo

Table 3 The matric potentials $\left(\Psi_{\mathrm{x}}\right)$ corresponding to volumetric water contents of 30,20,15 and 10\% in the different kinds of substrate samples. Cores extracted from mycorrhizal (M) and non-

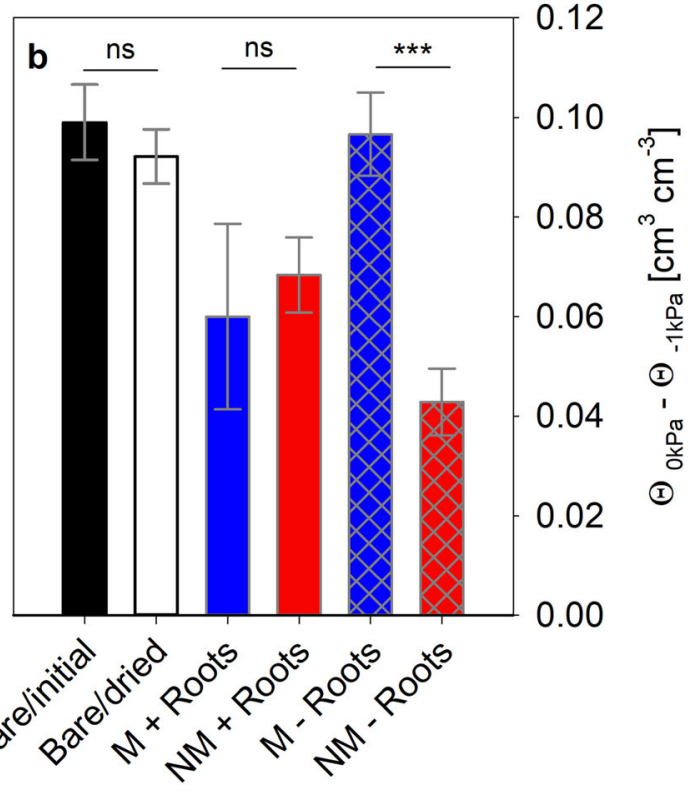

mycorrhizal (M, blue) substrates containing M. truncatula plants inoculated with $R$. irregularis. Asterisks indicated significant differences between non-mycorrhizal and mycorrhizal roots systems (t-test; N =4-6; \pm SE; ns, $P>0.05 ; * * *, P<0.001$ )

1997, 2004b). In addition, root water uptake inducing local soil drying constitutes a circular reference. Therefore, we conducted a simple test on unplanted substrates to check whether drying results in the expected shifts in water retention and if we avoided such effects in the pots by frequent compensatory irrigation.

In our bare and air-dried substrate water retention decreased from its initial state observed in unplanted and untreated substrates, especially in the moist area near saturation. Accordingly, this is expected for soils

mycorrhizal (NM) pots are shown separately. The matric potentials were interpolated on treatment-wise model fits

\begin{tabular}{llllll}
\hline Core type & Treatment & $\begin{array}{l}\Psi_{30} \\
{[\mathrm{kPa}]}\end{array}$ & $\begin{array}{l}\Psi_{20} \\
{[\mathrm{kPa}]}\end{array}$ & $\begin{array}{l}\Psi_{15} \\
{[\mathrm{kPa}]}\end{array}$ & $\begin{array}{l}\Psi_{10} \\
{[\mathrm{kPa}]}\end{array}$ \\
\hline Bare & Initial & -1.2 & -2.0 & -25.5 & -743.7 \\
& Dried & -1.0 & -1.9 & -9.1 & -372.5 \\
Planted (combined) & $\mathrm{M}$ & -1.5 & -3.0 & -32.2 & -868.7 \\
\multirow{4}{*}{+ Roots } & $\mathrm{NM}$ & -1.5 & -2.5 & -22.2 & -678.0 \\
& $\mathrm{M}$ & -1.7 & -3.4 & -39.3 & -991.1 \\
- Roots & $\mathrm{NM}$ & -1.5 & -2.7 & -18.6 & -602.0 \\
& $\mathrm{M}$ & -1.3 & -2.3 & -21.4 & -661.3 \\
& $\mathrm{NM}$ & -1.5 & -2.3 & -16.6 & -558.0 \\
\hline
\end{tabular}


that have undergone desiccation compared to soils that have not (Leij et al. 2002). Two mechanisms could explain it: (i) increase in water repellent conditions under which pores drain at lower matric potentials (Hallett 2008) with incomplete reversion of repellency during saturation or (ii) capillary-driven particle coalescence (Bodner et al. 2013a) at low matric potentials, which led to increased physical blocking of pore water access. The latter case is more likely to be causal for our findings because microbes that potentially exude surface active agents and induce biological pore clogging (Kandra et al. 2015; Seki and Miyazaki 2001) were previously killed in the unplanted substrates and the substrates were water saturated for $24 \mathrm{~h}$ before measurements. Water repellent conditions, if manifested during drying, are expected to be reversed after such time spans of water contact even in water repellent soils (Clothier et al. 2000). Since water release from large pores in the wet range between 0 and $-1 \mathrm{kPa}$ was not affected by air-drying the unplanted substrate (see Fig. 6), drying may have drawn particles of the organo-mineral soil component closer together with the rigid sand and zeolite particles. This could have resulted in the formation of air-filled cavities that persisted during the rather soft capillary saturation procedure, which would then reduce wet porosity.

By using large pots and frequent irrigation, we wanted to minimize the suction-induced confounding effects caused by different plant sizes surrounding the introduced cores. And in fact, no substantial (dryinginduced) loss of substrate wet porosity was measurable in any of the planted substrate zones. Assuming previously detected (c.f. Püschel et al. 2020 using the same model system) evapotranspiration rates of 19 and $22 \mathrm{~mL}$ $\mathrm{d}^{-1} \mathrm{~g}^{-1}$ shoot dry matter for $\mathrm{M}$ or NM pots for this experiment, these rates would have resulted in a total daily water loss of 129 and $84 \mathrm{~mL} \mathrm{~d}^{-1}$ in M or NM pots, respectively. Considering the pot size of $4.3 \mathrm{~L}$ and the target gravimetric water content of $22.17 \%$, this daily evapotranspiration would have reduced the gravimetric water content to $19.17 \%$ (or $\Theta=24.6 \%$ ) in $\mathrm{M}$ pots and to $20.22 \%$ (or $\Theta=25.8 \%$ ) in NM pots. Such changes are unlikely to have had strong impact on innercompartment properties due to water being drawn from outside, also because these water contents lie within a narrow range of high matric potentials (see Table 3 ).

When we fitted water retention models to root-free and root-containing substrates together, water retention was efficiently increased in M pots whereas the smaller non-mycorrhizal plants only preserved water storage of bare/initial substrates in wet and dry conditions. Moreover, the main water release in $\mathrm{M}$ substrates extended over a wider matric potential range. In the mycorrhizal setting, these changes in water retention induced to a bare substrate are consistent with the existence of bioinduced structural pore space. Enhancements in wet porosity are accompanied by a relative gain in larger and smaller pores at the expense of intermediate pore space (Bodner et al. 2014; Hayashi et al. 2006). By stabilizing or forming highly connected biopore systems roots could enhance substrate wet porosity $\left(\Theta_{\text {Sat }}\right)$ by mechanically forming or impeding collapse of large pores (Bodner et al. 2014; Nimmo 2004b). A more pronounced persistence of aggregates enlarges the pore space between and within aggregates (Nimmo 2004b). This corresponds to what we have observed for M-pots: at high matric potentials comparatively more water is released and, at lower matric potentials less water is released. This indicates that $\mathrm{M}$ plants have either induced a stronger formation of structural porosity than $\mathrm{NM}$ plants or that the structural pore system in M pots is more stable against saturation disturbance (as per the evaporation method) than that of NM substrates. Indeed, AMF are known for their positive effects on aggregate water stability in root-containing soils (Augé et al. 2001; Hallett et al. 2009; Rillig et al. 2002; Wilson et al. 2009).

The same weighting of root-free and root-containing substrates in fittings may provide indications for total pot water retention. However, this is more a crossingover of properties of two distinct substrate layers.

The curve shape parameters of water retention in rootcontaining cores reacted similarly to root morphology characteristics across NM and $\mathrm{M}$ pots, indicating that the roots in vicinity are the main cause for these changes. Compared to bare substrates, the root systems of both treatments induced water release distributions over a wider matric potential range, but only the coarser root systems in $\mathrm{M}$ pots enhanced the water volume that the substrate can contain and release. According to Bodner et al. (2014), coarse roots with considerable stiffness can exert mechanical strength to displace particles and promote air gap formation while fine roots use the available pore space to grow, increase the root-particle contact and promote aggregate coalescence through local drying, resulting in increased pore space heterogeneity. We showed that in both, M and NM root systems, the main root volume consists of fine roots (see Fig. 3), which possibly causes similar pore space heterogeneity and thus 
similarities in water release distribution over a wider range of matric potential than in bare/initial substrates (see $\sigma$ in Table 2). The consistent reduction of wet range water release (between 0 and $-1 \mathrm{kPa}$ ) and $\mathrm{r}_{\mathrm{m}}$ in $\mathrm{M}$ and NM substrates from that of unplanted substrates further supports the interpretation that similar fine root lengths across the inoculation treatments have caused similar occupancy and division of pre-existing pore spaces that exceeded the size of fine roots.

In contrast, the root systems of $\mathrm{M}$ plants had a much higher proportion of root volume, with coarser diameters, than those of NM plants. The large-diameter proportion of the root system likely required densification of the surrounding substrate because our homogenized substrate did not contain a pre-existing structural pore volume with pores exceeding the size of the largest roots (Lucas et al. 2019). The formation of a new biopore system may explain the higher wet porosity in Msubstrates with a higher proportion of stiffer roots than in NM substrates, as the introduced root volume was about eight times smaller than the increase in sat. A slightly higher root volume in M-substrates could also be accompanied by an enlarged rhizosphere, a zone of high water content (Moradi et al. 2011) and high amounts of exudates with surface active properties (Ahmed et al. 2014; Carminati et al. 2010; Carminati et al. 2011; Hallett et al. 2003; Kroener et al. 2018), possibly maintaining hydrophilic conditions under our management for moist substrates. This may also have contributed to consistently higher water retention measured in root-containing M-substrates than in NM substrates. The higher dry-end water retention in $\mathrm{M}$ substrates could also be caused by increased pore clogging of the smaller-sized pores, i.e. of the zeolite granules. Biological activity can result in clogging pores of zeolite granules, either by exudation or physically by microbial growth (Kandra et al. 2015; Seki and Miyazaki 2001) that can block water release from underneath the colonized region. Both, the release of organic compounds and physical blockage are likely higher for $\mathrm{M}$ substrates that contained AMF. This is because the filamentous growth form of these fungi is an efficient space filling structure on a finer scale than roots (Ritz and Young 2004) and AMF-associated bacteria can form biofilms on hyphal surfaces (Sharma et al. 2020).

We were also particularly interested in how water retention responds to the ingrowth of hyphae in root-free substrates. There is evidence that AMF per se may influence water retention as they (i) contributed to aggregation and repellency in compartments that excluded root penetration (Leifheit et al. 2015; Morris et al. 2019; Rillig et al. 2010; Rillig and Mummey 2006) and (ii) they affected water retention in substrates with root systems of similar morphology as in AMF-free counterparts (Augé et al. 2001; Bitterlich et al. 2018c). However, the latter cited studies do not directly separate effects of roots on water retention from those of hyphae.

Because hydraulic continuity persists across the rootexclusion mesh we need to consider that plant influences on root-free inner core volumes are not completely impeded (Hallett et al. 2009). We also observed this. Relative to bare/initial substrates, planting led to a similar increase of wet porosity in root-free substrates of $\mathrm{NM}$ and $\mathrm{M}$ pots. It was reported that plants can drive physico-chemical soil conditions in soil fractions remote to roots that were separated by meshes, including the transduction of wet-dry dynamics and exudates beyond the mesh (Hallett et al. 2009; Sauer et al. 2006). Although we estimated the wet-dry dynamics to be of little influence in planted pots, we cannot totally exclude this to still exert force across the mesh. Wet-dry dynamics can lead to macroporosity (Bodner et al. 2013a) and hence to increased water retention in moist ranges like we observed here in root-free NM substrates. Another possibility is that roots adjacent to the mesh with root hairs crossing it exude organic compounds into the inner core volume. Such exudates are, however, not expected to travel much further than the length of root hairs (Sauer et al. 2006) especially when they adhere to mineral particles. A so-called rhizosheath that is formed from plant exudates and adhering soil particles around roots essentially extends to the length of root hairs (Haling et al. 2010). We are not sure if effects of root exudation restricted to a 'surface layer' at the mesh of our compartments would have led to affecting water retention in the whole core. What we can safely assume though, is that only in M pots the root-free substrate was colonized by hyphae of AMF. This AMF presence has led to conservation of wet porosity and wet-end water release whilst comparatively increasing water release distribution over wider matric potential ranges. This corresponds in principle to what would be expected for stabilization of soil structure and aggregation (Bodner et al. 2014; Hayashi et al. 2006); a good internal substrate drainage whilst conserving water storage in the dry range (Bronick and Lal 2005). AMF hyphae seem capable of promoting water stable aggregation distant from roots (Leifheit et al. 2015; Morris et al. 2019) and 
can induce repellent conditions on the surface of aggregates (Rillig et al. 2010), which may protect aggregates from disintegration (Goebel et al. 2005). It has also been reported that $R$. irregularis was associated with pore spaces distributed to higher pore sizes (Martin et al. 2012). However, the stronger decline in wet-range water retention in root-free AMF substrates than in NM substrates would also be expected when AMF caused a decline in the surface tension of the substrate water; as has been observed for plant exudates (Read et al. 2003). But, we are unsure if this could be detected with our methodology that starts with an initial saturation in a water bath. It is feasible to assume that surface active effects of AMF in the soil, if present, have been abolished by long water contact times and dilution. To detangle such potential effects from AMF-induced modulations in pore size and distribution would be an intriguing task for further research.

What consequences do our findings indicate for water relations in AMF studies, for physiology

and experimentation?

We observed that the presence of AMF induced alterations in substrate water retention. We are not surprised because AMF are known to re-structure soils and this has been reviewed previously (Miller and Jastrow 2000; Rillig 2004; Rillig and Mummey 2006; Six et al. 2004; Leifheit et al. 2014). But what do our findings mean for plant water relations?

In this paper, we were reluctant to base interpretation on commonly used definitions such as 'plant available moisture ranges' or 'field capacity' for two reasons: (i) it would have depended on the definition used whether we find AMF effects to be influential on water contents in a particular range or value of suction and, (ii) these definitions may not be particularly useful for pot studies. For example, considering the field capacity as an equilibrium water content that is attained after drainage processes vanish to negligible degrees, this condition may be useful under field conditions to define plant available moisture. Since in the field precipitation is irregular and water can move outside the ambit of plants, the attainment of water contents at field capacity might be a frequent scenario for field conditions. But, frequent irrigation of pots that are managed for moisture contents relatively prolongs plant water uptake under ongoing percolation after the irrigation incident.
As revealed by a meta-analysis, the vast majority of studies on water relations in mycorrhizal plants derive from greenhouses and growth chambers (Augé et al. 2015) where pots are used. And although there is abundant literature on soil fungal involvement in aggregate stability and water repellency that imply changes to water retention, there is not much literature about AMF influences on soil water retention to compare our results directly to. And, the results found by others seem to be context dependent. Bearden (2001), Augé et al. (2001) and Bitterlich et al. (2018c) found AMF to comparatively encourage drainage from clayey vertisol, a fine sandy loam and an artificial substrate mix, respectively. This caused lower water contents at lower matric potentials in AMF pots and the onset of this effect seemed dependent on the growth substrate used. All these studies used zones of the growth substrate that comprised roots and AMF and in the latter two studies, root mass and morphology were similar across mycorrhizal and non-mycorrhizal soils. In our case, the substrate containing roots and hyphae contained a larger root system than the NM soils which may have been a reason for why we observed the opposite reaction in water retention. Accordingly, Daynes et al. (2013) found increases in water retention upon AMF inoculation on a substrate deriving from coarsely textured spoil soil varying with compost additions but they did not include the root morphology. We only know about one other study that uses root-exclusion compartments to assess AMF effects on water retention and this study found no changes in water retention upon hyphal colonization but hydraulic conductivity to be positively affected by AMF (Bitterlich et al. 2018a). It is impossible to draw any far-reaching conclusion from these limited data other than AMF effects on water retention properties are context dependent. All mentioned studies comprised different symbioses, treatments, growth times and soils/substrates. Yet, context dependency of AMF effects on water retention is not surprising because physical laws imply a texture dependency (Querejeta 2017) and the contribution of AMF to e.g. aggregation is texture dependent (Leifheit et al. 2014). Just like surface-active materials like mucilage exert texture dependent influences on water retention (Kroener et al. 2018), AMF might do as well. The influences of AMF on soil water retention (as the integrated trait for water availability) and their potential variability in different soils and substrates is currently not well understood but they can be real (as found here). 
It is widely known that plants sense underground moisture and that these regulatory mechanisms serve to cope with soil moisture variability (Carminati and Javaux 2020; Damour et al. 2010; Simonneau et al. 1998; Tardieu et al. 1992). However, the scientific literature on AMF exerting control on plant moisture reactions has mainly focused on effects in planta while neglecting effects of physical conditioning underground. Only in a minority of such studies, the soil matric potential as the stress parameter is reported (Augé 2001; Augé et al. 2015). We do not dare to conclude directly on the plant physiological moisture response based on our data. However, it appears justified to assume that plants would need different amounts of energy to extract the same amount of water from substrates that differ in matric potentials at particular water contents (see Table 3). This may lead to an adjusted stress state in mycorrhizal plants growing under equal soil moisture as nonmycorrhizal plants. We therefore believe that changed physical conditions underground merit attention when the physiological moisture response of plants is investigated. In order to investigate mycorrhizal contributions to plant water stress adaption in a more direct way, one could use a framework that quantifies water flow from bulk soils to root systems in conjunction with the metabolic and physiological reaction of plants to soil water depletion. As obtaining continuous soil water potential data down to dry conditions seems a challenge due to the limited measurement range of tensiometers, modeling frameworks that can account for differences in root morphology and distribution (Graefe et al. 2019) could be used based on measurements of soil hydraulic properties and root system properties. Such frameworks allow for quantification of water flows from bulk soils to root systems and if and when these water flows are altered by AMF presence. Then it could be investigated whether changes of bulk soil water flows are preceded or ignited by the often observed changes of AMF to molecular (aquaporins), metabolic (osmotica, hormones) and physiological (gas exchange) states of plants. Finally, this should be studied in real soils of different textures in the future. This is, yet, not well explored but expected to be texture dependent as soil texture determines e.g. how resistant a soil is to aggregation and how prone it is to pore clogging.

\section{Conclusions}

Direct hyphal water delivery to plants has been discussed as an underlying mechanism to influence the physiological reaction of plants to soil moisture. However, $1 \mathrm{~cm}^{3}$ of conducting hyphal volume would comprise approx. $12.7 \mathrm{~km}$ of cylindrical hyphae with an inner diameter of $10 \mu \mathrm{m}$. Hence, the advective flow in hyphae is probably more relevant for matter pools that slowly accumulate in planta like P (Bitterlich and Franken 2016; Kikuchi et al. 2016; Neumann and George 2004; Whiteside et al. 2019) than for water, which is consumed by plants in the highest quantity of all soil resources and continuously lost to the atmosphere. But the pore space harboring mycorrhizal hyphae can exceed their volume by dimensions while water transport properties in it being modulated to a substantial degree. An important question for future studies is whether soil colonization by AMF leads to physical conditioning of the soil that allows easier water movement to root systems and how this would contribute to the frequent observations that $\mathrm{AMF}$ confer drought tolerance. Just like mucilage seems to buffer limitations of root water availability against water content changes in the bulk soil (Ahmed et al. 2014; Schwartz et al. 2016), the hyphosphere may have similar properties albeit on a finer scale. And, the known contribution of AMF to soil aggregation also qualifies to alter underground water movement especially under low soil moisture when the macropore space between aggregates is air-filled because then soil water is exchanged between aggregate contacts (Carminati et al. 2007, 2008). Aggregation processes may further extent from the root system with a hyphal network and thus increase substrate hydraulic conductivity of a bulk substrate under dry conditions. At root entry points, hyphae of AMF may also constitute liquid bridges and preserve root-soil contact under increasing cavitation around roots during ongoing soil water depletion. For these reasons and our finding that physical conditioning of a substrate remote to roots by AMF takes place, we emphasize that future studies on the drought physiology of AMF symbioses should address both, reactions in planta and ex planta conditions. Finally, only with continuous criteria like water retention, contributions of AMF to root water uptake from bulk substrates can be studied in conjunction with mycorrhizainduced changes to root morphology, e.g. with frameworks like published in Graefe et al. (2019).

Acknowledgements We would like to thank Eva Rydlová and Jan Rydlo for technical support with the establishment and maintenance of the experiment and Zuzana Čermáková for assistance with the qPCR and elemental analyses. We would also like to thank the two anonymous reviewers for their detailed reviews, which greatly helped us to improve the manuscript. 
Funding Open Access funding enabled and organized by Projekt DEAL. This study was supported by the Czech Science Foundation (project 17-12166S) and by the Czech Academy of Sciences (long-term research development programs RVO 67985939 and RVO 61388971). The IGZ is funded by the Ministry of Food and Agriculture of the Federal Republic of Germany, from the Ministry for Science, Research and Culture of the State of Brandenburg. Richard Pauwels PHD project is funded by the Leibniz Collaborative Exzellenz (K102/2018).

Open Access This article is licensed under a Creative Commons Attribution 4.0 International License, which permits use, sharing, adaptation, distribution and reproduction in any medium or format, as long as you give appropriate credit to the original author(s) and the source, provide a link to the Creative Commons licence, and indicate if changes were made. The images or other third party material in this article are included in the article's Creative Commons licence, unless indicated otherwise in a credit line to the material. If material is not included in the article's Creative Commons licence and your intended use is not permitted by statutory regulation or exceeds the permitted use, you will need to obtain permission directly from the copyright holder. To view a copy of this licence, visit http://creativecommons.org/licenses/by/4.0/.

\section{References}

Ahmed MA, Kroener E, Holz M, Zarebanadkouki M, Carminati A (2014) Mucilage exudation facilitates root water uptake in dry soils. Funct Plant Biol 41:1129-1137

Ahmed MA, Kroener E, Benard P, Zarebanadkouki M, Kaestner A, Carminati A (2016) Drying of mucilage causes water repellency in the rhizosphere of maize: measurements and modelling. Plant Soil 407:161-171

Allen MF (2007) Mycorrhizal fungi: highways for water and nutrients in arid soils. Vadose Zone J 6:291-297

Aroca R, Porcel R, Ruiz-Lozano JM (2007) How does arbuscular mycorrhizal symbiosis regulate root hydraulic properties and plasma membrane aquaporins in Phaseolus vulgaris under drought, cold or salinity stresses? New Phytol 173:808-816

Augé RM (2001) Water relations, drought and vesiculararbuscular mycorrhizal symbiosis. Mycorrhiza 11:3-42

Augé RM (2004) Arbuscular mycorrhizae and soil/plant water relations. Can J Soil Sci 84:373-381

Augé RM, Stodola AJ, Tims JE, Saxton AM (2001) Moisture retention properties of a mycorrhizal soil. Plant Soil 230:8797

Augé RM, Toler HD, Saxton AM (2015) Arbuscular mycorrhizal symbiosis alters stomatal conductance of host plants more under drought than under amply watered conditions: a metaanalysis. Mycorrhiza 25:13-24

Bárzana G, Aroca R, Bienert GP, Chaumont F, Ruiz-Lozano JM (2014) New insights into the regulation of aquaporins by the arbuscular mycorrhizal symbiosis in maize plants under drought stress and possible implications for plant performance. Mol Plant-Microbe Interact 27:349-363
Bearden BN (2001) Influence of arbuscular mycorrhizal fungi on soil structure and soil water characteristics of vertisols. Plant Soil 229:245-258

Bengough AG, MacKenzie CJ (1994) Simultaneous measurement of root force and elongation for seedling pea roots. J Exp Bot 45:95-102. https://doi.org/10.1093/jxb/45.1.95

Berta G, Fusconi A, Trotta A, Scannerini S (1990) Morphogenetic modifications induced by the mycorrhizal fungus Glomus strain E3 in the root system of Allium porrum L. New Phytol 114:207-215

Bitterlich M, Franken P (2016) Connecting polyphosphate translocation and hyphal water transport points to a key of mycorrhizal functioning. New Phytol 211:1147-1149

Bitterlich M, Franken P, Graefe J (2018a) Arbuscular mycorrhiza improves substrate hydraulic conductivity in the plant available moisture range under root growth exclusion. Front Plant Sci 9:301

Bitterlich M, Rouphael Y, Graefe J, Franken P (2018b) Arbuscular mycorrhizas: a promising component of plant production systems provided favorable conditions for their growth. Front Plant Sci 9:1329

Bitterlich M, Sandmann M, Graefe J (2018c) Arbuscular mycorrhiza alleviates restrictions to substrate water flow and delays transpiration limitation to stronger drought in tomato. Front Plant Sci 9:154

Bitterlich M, Franken P, Graefe J (2019) Atmospheric drought and low light impede mycorrhizal effects on leaf photosynthesis - a glasshouse study on tomato under naturally fluctuating environmental conditions. Mycorrhiza 29: 13-28

Bodner G, Scholl P, Kaul H-P (2013a) Field quantification of wetting-drying cycles to predict temporal changes of soil pore size distribution. Soil Tillage Res 133:1-9

Bodner G, Scholl P, Loiskandl W, Kaul H-P (2013b) Environmental and management influences on temporal variability of near saturated soil hydraulic properties. Geoderma 204:120-129

Bodner G, Leitner D, Kaul H-P (2014) Coarse and fine root plants affect pore size distributions differently. Plant Soil 380:133151

Bronick CJ, Lal R (2005) Soil structure and management: a review. Geoderma 124:3-22

Burr-Hersey JE, Bengough AG, Ritz K, Mooney SJ (2020) Reorganisation of rhizosphere soil pore structure by wild plant species in compacted soils. Journal of Experimental Botany in press. https://doi.org/10.1093/jxb/eraa323

Carminati A, Javaux M (2020) Soil rather than xylem vulnerability controls stomatal response to drought. Trends Plant Sci 25: 868-880

Carminati A, Kaestner A, Ippisch O, Koliji A, Lehmann P, Hassanein R, Vontobel P, Lehmann E, Laloui L, Vulliet L, Flühler H (2007) Water flow between soil aggregates. Transp Porous Media 68:219-236

Carminati A, Kaestner A, Lehmann P, Flühler H (2008) Unsaturated water flow across soil aggregate contacts. Adv Water Resour 31:1221-1232

Carminati A, Moradi AB, Vetterlein D, Vontobel P, Lehmann E, Weller U, Vogel HJ, Oswald SE (2010) Dynamics of soil water content in the rhizosphere. Plant Soil 332:163-176

Carminati A, Schneider CL, Moradi AB, Zarebanadkouki M, Vetterlein D, Vogel HJ, Hildebrandt A, Weller U, Schüler 
L, Oswald SE (2011) How the rhizosphere may favor water availability to roots. Vadose Zone J 10:988-998

Carminati A, Benard P, Ahmed MA, Zarebanadkouki M (2017) Liquid bridges at the root-soil interface. Plant Soil 417:1-15

Clothier B, Vogeler I, Magesan G (2000) The breakdown of water repellency and solute transport through a hydrophobic soil. J Hydrol 231:255-264

Couillerot O et al (2013) Comparison of prominent Azospirillum strains in Azospirillum-Pseudomonas-Glomus consortia for promotion of maize growth. Appl Microbiol Biotechnol 97: 4639-4649

Damour G, Simonneau T, Cochard H, Urban L (2010) An overview of models of stomatal conductance at the leaf level. Plant Cell Environ 33:1419-1438

Daynes CN, Field DJ, Saleeba JA, Cole MA, McGee PA (2013) Development and stabilisation of soil structure via interactions between organic matter, arbuscular mycorrhizal fungi and plant roots. Soil Biol Biochem 57:683-694

Driver JD, Holben WE, Rillig MC (2005) Characterization of glomalin as a hyphal wall component of arbuscular mycorrhizal fungi. Soil Biol Biochem 37:101-106

Durner W (1992) Predicting the unsaturated hydraulic conductivity using multi-porosity water retention curves Indirect methods for estimating the hydraulic properties of unsaturated soils:185-202

Feeney DS, Crawford JW, Daniell T, Hallett PD, Nunan N, Ritz K, Rivers M, Young IM (2006) Three-dimensional microorganization of the soil-root-microbe system. Microb Ecol 52:151-158

Friese CF, Allen MF (1991) The spread of VA mycorrhizal fungal hyphae in the soil: inoculum types and external hyphal architecture. Mycologia 83:409-418

Gadkar V, Rillig MC (2006) The arbuscular mycorrhizal fungal protein glomalin is a putative homolog of heat shock protein 60. FEMS Microbiol Lett 263:93-101

Gamalero E, Trotta A, Massa N, Copetta A, Martinotti MG, Berta G (2004) Impact of two fluorescent pseudomonads and an arbuscular mycorrhizal fungus on tomato plant growth, root architecture and $\mathrm{P}$ acquisition. Mycorrhiza 14:185-192

George E, Häussler K-U, Vetterlein D, Gorgus E, Marschner H (1992) Water and nutrient translocation by hyphae of Glomus mosseae. Can J Bot 70:2130-2137

Głąb T, Ścigalska B, Labuz B (2013) Effect of crop rotations with triticale $(\times$ Triticosecale Wittm.) on soil pore characteristics Geoderma 202-203:1-7 doi: https://doi.org/10.1016/j. geoderma.2013.03.002

Goebel M-O, Bachmann J, Woche SK, Fischer WR (2005) Soil wettability, aggregate stability, and the decomposition of soil organic matter. Geoderma 128:80-93

Graefe J, Prüfert U, Bitterlich M (2019) Extension of the cylindrical root model for water uptake to non-regular root distributions. Vadose Zone J 18:1-11

Gryndler M, Šmilauer P, Püschel D, Bukovská P, Hršelová H, Hujslová M, Gryndlerová H, Beskid O, Konvalinková T, Jansa J (2018) Appropriate nonmycorrhizal controls in arbuscular mycorrhiza research: a microbiome perspective. Mycorrhiza 28:435-450

Haling RE, Richardson AE, Culvenor RA, Lambers H, Simpson RJ (2010) Root morphology, root-hair development and rhizosheath formation on perennial grass seedlings is influenced by soil acidity. Plant Soil 335:457-468
Hallett PD (2008) A brief overview of the causes, impacts and amelioration of soil water repellency-a review. Soil and Water Research 3:521-528

Hallett P, Gordon D, Bengough A (2003) Plant influence on rhizosphere hydraulic properties: direct measurements using a miniaturized infiltrometer. New Phytol 157:597-603

Hallett PD, Feeney DS, Bengough AG, Rillig MC, Scrimgeour CM, Young IM (2009) Disentangling the impact of AM fungi versus roots on soil structure and water transport. Plant Soil 314:183-196

Hayashi Y, Ken'ichirou K, Mizuyama T (2006) Changes in pore size distribution and hydraulic properties of forest soil resulting from structural development. J Hydrol 331:85-102

Helliwell JR, Sturrock CJ, Miller AJ, Whalley WR, Mooney SJ (2019) The role of plant species and soil condition in the structural development of the rhizosphere. Plant Cell Environ 42:1974-1986

Iden SC, Durner W (2014) Comment on "simple consistent models for water retention and hydraulic conductivity in the complete moisture range" by A. Peters. Water Resour Res 50:7530-7534

Iijima M, Higuchi T, Barlow PW (2004) Contribution of root cap mucilage and presence of an intact root cap in maize (Zea mays) to the reduction of soil mechanical impedance. Ann Bot 94:473-477. https://doi.org/10.1093/aob/mch166

Jansa J, Mozafar A, Kuhn G, Anken T, Ruh R, Sanders IR, Frossard E (2003) Soil tillage affects the community structure of mycorrhizal fungi in maize roots. Ecol Appl 13:1164 1176

Jansa J, Bukovská P, Gryndler M (2013) Mycorrhizal hyphae as ecological niche for highly specialized hypersymbionts - or just soil free-riders? Front Plant Sci 4:134

Kandra HS, Callaghan J, Deletic A, McCarthy DT (2015) Biological clogging in storm water filters. J Environ Eng 141:04014057

Kikuchi Y et al (2016) Aquaporin-mediated long-distance polyphosphate translocation directed towards the host in arbuscular mycorrhizal symbiosis: application of virusinduced gene silencing. New Phytol 211:1202-1208

Kosugi K (1994) Three-parameter lognormal distribution model for soil water retention. Water Resour Res 30:891-901

Kosugi K, Hopmans J (1998) Scaling water retention curves for soils with lognormal pore-size distribution. Soil Sci Soc Am J 62:1496-1505

Kroener E, Holz M, Zarebanadkouki M, Ahmed M, Carminati A (2018) Effects of mucilage on rhizosphere hydraulic functions depend on soil particle size. Vadose Zone J:17

Leifheit EF, Veresoglou SD, Lehmann A, Morris EK, Rillig MC (2014) Multiple factors influence the role of arbuscular mycorrhizal fungi in soil aggregation - a meta-analysis. Plant Soil 374:523-537

Leifheit E, Verbruggen E, Rillig M (2015) Arbuscular mycorrhizal fungi reduce decomposition of woody plant litter while increasing soil aggregation. Soil Biol Biochem 81:323-328

Leij FJ, Ghezzehei TA, Or D (2002) Modeling the dynamics of the soil pore-size distribution. Soil Tillage Res 64:61-78

Lucas M, Schlüter S, Vogel H-J, Vetterlein D (2019) Roots compact the surrounding soil depending on the structures they encounter. Sci Rep 9:1-13

Lucas M, Vetterlein D, Vogel HJ, Schlüter S (2020) Revealing pore connectivity across scales and resolutions with X-ray 
CT European Journal of Soil Science In press. https://doi. org/10.1111/ejss.12961

Martin S, Mooney S, Dickinson M, West H (2012) The effects of simultaneous root colonisation by three Glomus species on soil pore characteristics. Soil Biol Biochem 49:167-173

Materechera S, Kirby J, Alston A, Dexter A (1994) Modification of soil aggregation by watering regime and roots growing through beds of large aggregates. Plant Soil 160:57-66

Miller R, Jastrow J (2000) Mycorrhizal fungi influence soil structure. In: Arbuscular mycorrhizas: Physiology and Function. Springer, pp 3-18

Moradi AB, Carminati A, Vetterlein D, Vontobel P, Lehmann E, Weller U, Hopmans JW, Vogel HJ, Oswald SE (2011) Three-dimensional visualization and quantification of water content in the rhizosphere. New Phytol 192:653-663

Morris EK, Morris D, Vogt S, Gleber S-C, Bigalke M, Wilcke W, Rillig M (2019) Visualizing the dynamics of soil aggregation as affected by arbuscular mycorrhizal fungi. The ISME Journal 13:1639-1646

Neumann E, George E (2004) Colonisation with the arbuscular mycorrhizal fungus Glomus mosseae (Nicol. \& Gerd.) enhanced phosphorus uptake from dry soil in Sorghum bicolor (L.). Plant Soil 261:245-255

Nimmo JR (1997) Modeling structural influences on soil water retention. Soil Sci Soc Am J 61:712-719

Nimmo JR (2004a) Aggregation: physical aspects encyclopedia of soils in the environment academic press, London

Nimmo JR (2004b) Porosity and pore size distribution encyclopedia of soils in the Environment 3:295-303

Peters A (2013) Simple consistent models for water retention and hydraulic conductivity in the complete moisture range. Water Resour Res 49:6765-6780

Peters A (2014) Reply to comment by S. Iden and W. Durner on "simple consistent models for water retention and hydraulic conductivity in the complete moisture range". Water Resour Res 50:7535-7539

Porcel R, Ruiz-Lozano JM (2004) Arbuscular mycorrhizal influence on leaf water potential, solute accumulation, and oxidative stress in soybean plants subjected to drought stress. J Exp Bot 55:1743-1750

Porcel R, Aroca R, Azcon R, Ruiz-Lozano JM (2006) PIP aquaporin gene expression in arbuscular mycorrhizal Glycine max and Lactuca sativa plants in relation to drought stress tolerance. Plant Mol Biol 60:389-404

Püschel D, Janoušková M, Voříšková A, Gryndlerová H, Vosátka M, Jansa J (2017) Arbuscular mycorrhiza stimulates biological nitrogen fixation in two Medicago spp. through improved phosphorus acquisition. Front Plant Sci 8:390

Püschel D, Bitterlich M, Rydlová J, Jansa J (2020) Facilitation of plant water uptake by an arbuscular mycorrhizal fungus: a Gordian knot of roots and hyphae. Mycorrhiza 30:299-313

Querejeta J (2017) Soil water retention and availability as influenced by mycorrhizal symbiosis: consequences for individual plants, communities, and ecosystems. In: Mycorrhizal Mediation of Soil. Elsevier, pp. 299-317

Raven JA, Edwards D (2001) Roots: evolutionary origins and biogeochemical significance. J Exp Bot 52:381-401

Rawls W, Gish T, Brakensiek D (1991) Estimating soil water retention from soil physical properties and characteristics. Advances in Soil Science. Springer, In, pp 213-234
Read D et al (2003) Plant roots release phospholipid surfactants that modify the physical and chemical properties of soil. New Phytol 157:315-326

Rillig MC (2004) Arbuscular mycorrhizae, glomalin, and soil aggregation. Can J Soil Sci 84:355-363

Rillig MC (2005) A connection between fungal hydrophobins and soil water repellency? Pedobiologia 49:395-399

Rillig MC, Mummey DL (2006) Mycorrhizas and soil structure. New Phytol 171:41-53

Rillig MC, Wright SF, Eviner VT (2002) The role of arbuscular mycorrhizal fungi and glomalin in soil aggregation: comparing effects of five plant species. Plant Soil 238:325-333

Rillig MC, Mardatin NF, Leifheit EF, Antunes PM (2010) Mycelium of arbuscular mycorrhizal fungi increases soil water repellency and is sufficient to maintain water-stable soil aggregates. Soil Biol Biochem 42:1189-1191

Rillig MC, Aguilar-Trigueros CA, Bergmann J, Verbruggen E, Veresoglou SD, Lehmann A (2015) Plant root and mycorrhizal fungal traits for understanding soil aggregation. New Phytol 205:1385-1388

Ritz K, Young IM (2004) Interactions between soil structure and fungi. Mycologist 18:52-59

Ruiz-Lozano J, Azcón R, Gomez M (1995) Effects of arbuscularmycorrhizal glomus species on drought tolerance: physiological and nutritional plant responses. Appl Environ Microbiol 61:456-460

Sauer D, Kuzyakov Y, Stahr K (2006) Spatial distribution of root exudates of five plant species as assessed by ${ }^{14} \mathrm{C}$ labeling. $\mathrm{J}$ Plant Nutr Soil Sci 169:360-362

Schindler U, Durner W, von Unold G, Müller L (2010) Evaporation method for measuring unsaturated hydraulic properties of soils: Extending the measurement range. Soil Sci Soc Am J 74:1071-1083

Scholl P, Leitner D, Kammerer G, Loiskandl W, Kaul H-P, Bodner G (2014) Root induced changes of effective 1D hydraulic properties in a soil column. Plant Soil 381:193-213

Schwartz N, Carminati A, Javaux M (2016) The impact of mucilage on root water uptake-A numerical study. Water Resour Res 52:264-277

Segal E, Kushnir T, Mualem Y, Shani U (2008) Water uptake and hydraulics of the root hair rhizosphere. Vadose Zone $\mathrm{J}$ 7: $1027-1034$

Seki K, Miyazaki T (2001) A mathematical model for biological clogging of uniform porous media. Water Resour Res 37: 2995-2999. https://doi.org/10.1029/2001wr000395

Sharma S, Compant S, Ballhausen M-B, Ruppel S, Franken P (2020) The interaction between Rhizoglomus irregulare and hyphae attached phosphate solubilizing bacteria increases plant biomass of Solanum lycopersicum. Microbiol Res: 126556

Simonneau T, Barrieu P, Tardieu F (1998) Accumulation rate of ABA in detached maize roots correlates with root water potential regardless of age and branching order. Plant Cell Environ 21:1113-1122

Six J, Bossuyt H, Degryze S, Denef K (2004) A history of research on the link between (micro) aggregates, soil biota, and soil organic matter dynamics. Soil Tillage Res 79:7-31

Somasegaran P, Hoben HJ (1994) Quantifying the growth of rhizobia. Handbook for rhizobia. Springer, In, pp 47-57 
Steinberg PD, Rillig MC (2003) Differential decomposition of arbuscular mycorrhizal fungal hyphae and glomalin. Soil Biol Biochem 35:191-194

Tardieu F, Zhang J, Katerji N, Bethenod O, Palmer S, Davies W (1992) Xylem ABA controls the stomatal conductance of field-grown maize subjected to soil compaction or soil drying. Plant Cell Environ 15:193-197

Thonar C, Erb A, Jansa J (2012) Real-time PCR to quantify composition of arbuscular mycorrhizal fungal communities - marker design, verification, calibration and field validation. Mol Ecol Resour 12:219-232

Tisdall JM, Oades JM (1982) Organic matter and water-stable aggregates in soils. J Soil Sci 33:141-163

Trouvelot A, Kough J, Gianinazzi-Pearson V (1986) Mesure du taux de mycorhization VA d'un système radiculaire. Recherche de méthode d'estimation ayant une signification fonctionnelle. In: Physiological and genetical aspects of mycorrhizae: proceedings of the 1st european symposium on mycorrhizae, Dijon, 1-5 July 1985, pp 217-221

Vierheilig H, Coughlan AP, Wyss U, Piché Y (1998) Ink and vinegar, a simple staining technique for arbuscularmycorrhizal fungi. Appl Environ Microbiol 64:5004-5007

Vollsnes AV, Futsaether CM, Bengough AG (2010) Quantifying rhizosphere particle movement around mutant maize roots using time-lapse imaging and particle image velocimetry. Eur J Soil Sci 61:926-939. https://doi.org/10.1111/j.13652389.2010.01297.x
Whiteside MD et al (2019) Mycorrhizal fungi respond to resource inequality by moving phosphorus from rich to poor patches across networks. Curr Biol 29:2043-2050. e2048

Wiersum L (1957) The relationship of the size and structural rigidity of pores to their penetration by roots. Plant Soil 9: 75-85

Wilson GW, Rice CW, Rillig MC, Springer A, Hartnett DC (2009) Soil aggregation and carbon sequestration are tightly correlated with the abundance of arbuscular mycorrhizal fungi: results from long-term field experiments. Ecol Lett 12:452-461

Wright SF, Upadhyaya A (1998) A survey of soils for aggregate stability and glomalin, a glycoprotein produced by hyphae of arbuscular mycorrhizal fungi. Plant Soil 198:97-107

Wu Q-S, Zou Y-N, He X-H (2010) Contributions of arbuscular mycorrhizal fungi to growth, photosynthesis, root morphology and ionic balance of citrus seedlings under salt stress. Acta Physiol Plant 32:297-304

Zou Y-N, Wu H-H, Giri B, Wu Q-S, Kuča K (2019) Mycorrhizal symbiosis down-regulates or does not change root aquaporin expression in trifoliate orange under drought stress. Plant Physiol Biochem 144:292-299

Publisher's note Springer Nature remains neutral with regard to jurisdictional claims in published maps and institutional affiliations. 